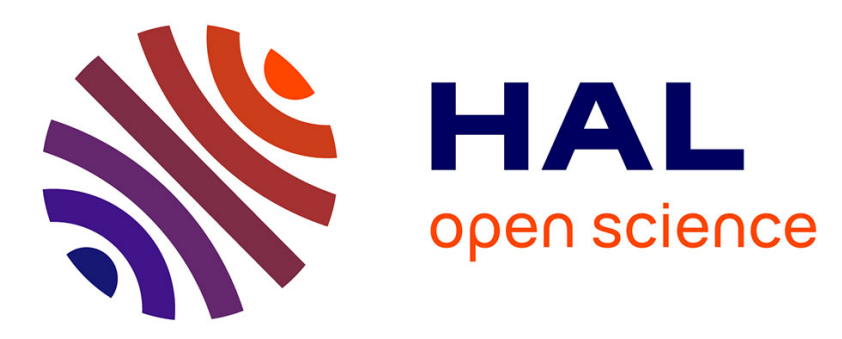

\title{
Reconnaissance de trois villes musulmanes de l'époque médiévale dans l'Ifat
}

François-Xavier Fauvelle, Bertrand Hirsch, Laurent Bruxelles, Chalachew Mesfin, Amélie Chekroun, Deresse Ayenatchew

\section{- To cite this version:}

François-Xavier Fauvelle, Bertrand Hirsch, Laurent Bruxelles, Chalachew Mesfin, Amélie Chekroun, et al. Reconnaissance de trois villes musulmanes de l'époque médiévale dans l'Ifat. Annales d'Éthiopie, 2006, 22 (1), pp.133-175. hal-02017897

\section{HAL Id: hal-02017897 \\ https://hal-univ-tlse2.archives-ouvertes.fr/hal-02017897}

Submitted on 24 Nov 2019

HAL is a multi-disciplinary open access archive for the deposit and dissemination of scientific research documents, whether they are published or not. The documents may come from teaching and research institutions in France or abroad, or from public or private research centers.
L'archive ouverte pluridisciplinaire HAL, est destinée au dépôt et à la diffusion de documents scientifiques de niveau recherche, publiés ou non, émanant des établissements d'enseignement et de recherche français ou étrangers, des laboratoires publics ou privés. 


\section{Reconnaissance de trois villes musulmanes de l'époque médiévale} dans l'Ifat

François-Xavier Fauvelle-Aymar, Bertrand Hirsch, Laurent Bruxelles, Chalachew Mesfin, Amélie Chekroun, Deresse Ayenatchew

\section{Citer ce document / Cite this document :}

Fauvelle-Aymar François-Xavier, Hirsch Bertrand, Bruxelles Laurent, Mesfin Chalachew, Chekroun Amélie, Ayenatchew Deresse. Reconnaissance de trois villes musulmanes de l'époque médiévale dans l'Ifat. In: Annales d'Ethiopie. Volume 22, année 2006. pp. 133-175;

http://www.persee.fr/doc/ethio_0066-2127_2006_num_22_1_1486

Document généré le 25/01/2017 


\begin{abstract}
The Ethiopian region of Ifat (North Shoa) has long been known as the cradle where Muslim kingdoms flourished during the Middle Ages, between the 13th to the 16th century. This region also was a very important emporium, which was revived in the 19th century with the growing of market places such as Aleyyu Amba. However, if the history of this region is relatively well-known from written sources, a very limited number of archaeological reconnaissances have been done to identify and describe the ancient remains. The area surveyed during this mission is situated some $20 \mathrm{~km}$ south-east of Shoa Robit, at an altitude of $1250-1300$ meters. Several sites were identified.

Situated $1,5 \mathrm{~km}$ on the left-hand side of the road from Säfi-Beret to Kumamé, the site of Asbari is found on a small plateau. The mosque we found there has already described by other scholars : it is possibly the largest ancient mosque of Ethiopia. Several other buildings displaying mihrab are also present on the site, as well as a Muslim graveyard comprising several hundred tombs. The town itself is walled. The structures still visible appear to be scattered and the remaining walls have a very low elevation. On the same range of hills, several Muslim sites were identified. Situated $1 \mathrm{~km}$ from Kedä Bura, the area of Mäsal displays many Muslim tombs and at least one tumulus. Another Muslim cemetery is found at the top of the slope near the edge of the plateau. Another three tumulus were found in the part of the cemetery where the most ancient tombs are located. This cemetery is walled. At the top of the hill, to the south of the cemetery, the ruins of a mosque locally called Mäsgid Lé-alé. The mosque of Rassa Guba is situated to the north-east of Kedä Bura ; only the north wall remains. North of Kedä Bura, a large Muslim cemetery was found : it is still in use and the local inhabitants call it Hajji Mansur. Among ancient and recent tombs, a unique sepulture already described par Chernet Tilahun (1990) was found : it is a monolithic structure engraved with an Arabic inscription.

The site of Nora is located one hour on foot from the Argobba village of Wosisso. Many ruins were found there, presenting a very dense aspect, with walls displaying up to 2 meters of elevation. A network of paved street is still visible. The buildings are distinctly quadrangular and reminiscent of Argobba or Harari traditional architecture. The town is walled, with gates. The mosque is located at the highest point of the site ; its size is $13.20 \times 12.20 \mathrm{~m}$, with walls reaching 5 meters. In the north-east corner of the mosque, a low passage was found to be the entrance of the stairway leading to a now partly-destroyed minaret. A flat area not far from the mosque displays dozens of Muslim sepultures. The whole site delivers a great number of pottery shards as well as obsidian artifacts; the remains are particularly abundant nearby an archaeological tell situated $200 \mathrm{~m}$ to the north-east of the mosque, and which might be a tumulus. At least three other tumulus were identified inside the town.
\end{abstract}

\title{
Résumé
}

Plusieurs sites en ruines d'époque médiévale, dont trois villes, ont été identifiés par les auteurs du présent article à quelque $20 \mathrm{~km}$ au sud-est de la ville de Choa Robit, à environ $1300 \mathrm{~m}$ d'altitude dans l'escarpement de la vallée du Rift ; ces sites livrent des mosquées, des quartiers d'habitations, des murailles d'enceinte, des nécropoles musulmanes. Ces villes disparues sont probablement les premiers témoignages matériels des royaumes musulmans connus par les textes pour avoir fleuri dans I'Ifat entre le Xe et le XVle siècle. 


\title{
RECONNAISSANCE \\ DE TROIS VILLES MUSULMANES \\ DE L'ÉPOQUE MÉDIÉVALE DANS L'IFAT
}

\author{
François-Xavier FAuvelle-AyMar, Bertrand Hirsch, Laurent \\ Bruxelles, Chalachew Mesfin, Amélie Chekroun, \\ Deresse Ayenatchew
}

$* * * * * * * * * * * * * *$

\section{Résumé}

Plusieurs sites en ruines d'époque médiévale, dont trois villes, ont été identifiés par les auteurs du présent article à quelque $20 \mathrm{~km}$ au sud-est de la ville de Choa Robit, à environ $1300 m$ d'altitude dans l'escarpement de la vallée du Rift; ces sites livrent des mosquées, des quartiers d'habitations, des murailles d'enceinte, des nécropoles musulmanes. Ces villes disparues sont probablement les premiers témoignages matériels des royaumes musulmans connus par les textes pour avoir fleuri dans l'Ifat entre le $X^{e}$ et le $X V T^{e}$ sièle.

Mots-clés : Éthiopie, Ifat, archéologie, histoire, villes, Moyen-Âge

\begin{abstract}
The Ethiopian region of Ifat (North Shoa) has long been known as the cradle where Muslim kingdoms flourished during the Middle Ages, between the $13^{\text {th }}$ to the $16^{\text {th }}$ century. This region also was a very important emporium, which was revived in the $19^{\text {th }}$ century with the growing of market places such as Aleyyu Amba. However, if the bistory of this region is relatively well-known from written sources, a very limited number of archaeological reconnaissances have been done to identify and describe the ancient remains. The area surveyed during this mission is situated some $20 \mathrm{~km}$ south-east of Shoa Robit, at an altitude of 1250-1300 meters. Several sites were identified.

Situated 1,5km on the left-hand side of the road from Säfi-Beret to Kumamé, the site of Asbäri is found on a small plateau. The mosque we found there has already described by other scholars: it is possibly the largest ancient mosque of Ethiopia. Several other buildings displaying mibrab are also present on the site, as
\end{abstract}




\section{François-Xavier FAUVtil. H-AYMAR $e t$ al.}

well as a Muslim graveyard comprising several bundred tombs. The town itself is walled. The structures still visible appear to be scattered and the remaining walls bave a very low elevation.

On the same range of bills, several Muslim sites were identified. Situated $1 \mathrm{~km}$ from Kedä Bura, the area of Mäsal displays many Muslim tombs and at least one tumulus. Another Muslim cemetery is found at the top of the slope near the edge of the plateau. Another three tumulus were found in the part of the cemetery where the most ancient tombs are located. This cemetery is walled. At the top of the hill, to the south of the cemetery, the ruins of a mosque locally called Mäsgid Lé-alé. The mosque of Rassa Guba is situated to the north-east of Kedä Bura; only the north wall remains. North of Kedä Bura, a large Muslim cemetery was found: it is still in use and the local inbabitants call it Haji Mansur. Among ancient and recent tombs, a unique sepulture already described par Chernet Tilabun (1990) was found: it is a monolithic structure engraved with an Arabic inscription.

The site of Nora is located one hour on foot from the Argobba village of Wosisso. Many ruins were found there, presenting a very dense aspect, with walls displaying up to 2 meters of elevation. A network of paved street is still visible. The buildings are distinctly quadrangular and reminiscent of Argobba or Harari traditional architecture. The town is walled, with gates. The mosque is located at the highest point of the site; its size is $13.20 \times 12.20 \mathrm{~m}$, with walls reaching 5 meters. In the north-east corner of the mosque, a low passage was found to be the entrance of the stairway leading to a now partly-destroyed minaret. A flat area not far from the mosque displays dozens of Muslim sepultures. The whole site delivers a great number of pottery shards as well as obsidian artifacts; the remains are particularly abundant nearby an archaeological tell situated $200 \mathrm{~m}$ to the north-east of the mosque, and which might be a tumulus. At least three other tumulus were identified inside the town.

Keywords : Ethiopia, Ifat, Archaeology, History, Towns, Middle Ages

$* * * * * * * * * * * * * *$

L'Ifat (⒋7) (région du Nord-Choa) est reconnue depuis longtemps comme la zone où s'établirent plusieurs royaumes musulmans depuis l'époque médiévale - en premier lieu les royaumes du Choa puis de l'Ifat entre le $\mathrm{X}^{\mathrm{e}}$ et le XVI $\mathrm{X}^{\mathrm{c}}$ siècles. À l'interface du monde chré- 


\section{RECONNAISSANCE DE TROIS VILLES MUSULMANES}

tien et en connexion avec le golfe d'Aden, cette région a été également un très important carrefour commercial à l'époque médiévale, revitalisé

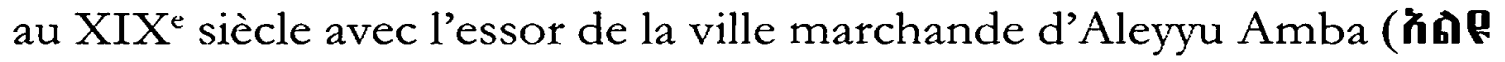
h๊ण0). Enfin, c'est une région où l'on trouve encore aujourd'hui des populations argobba $(\boldsymbol{\hbar} \mathbf{C} \mathbf{7} \cdot \mathbf{I})$, qui se revendiquent comme descendantes des habitants et des élites politiques du royaume de l'Ifat (XIII ${ }^{c_{-}}$ $\mathrm{XV}^{\mathrm{c}}$ siècles) et qui ont conservé une mémoire de la géographie historique de ce territoire, savent identifier les lieux anciens, mosquées et ruines, qui témoignent de la splendeur passée du royaume de l'Ifat.

Mais si l'histoire de cette région est relativement connue par les documents historiques en arabe qui décrivent l'histoire des dynasties locales (Mahzumites puis Walasma mnnणप), par les sources geez détaillant les conflits avec le royaume des Salomoniens et par le Fiutub el-Habasha, il y a eu très peu de travaux de prospections archéologiques pour reconnaître et décrire les ruines de l'époque médiévale. Pourtant dès 1893, le Dr Traversi (Traversi, 1893) signalait l'intérêt des ruines de Warkamba (PC' 37) et de Rassa ( $\mathbf{H}$ ). Dans deux brèves lettres adressées au président de la Société italienne de géographie, il donne quelques informations sur son passage dans la région en juin 1893, envoyé sur place par le roi Ménélik qui voulait faire vérifier l'existence de villes anciennes près de Rassa et de Chänno (K $\mathbf{5}^{\circ}$ ) et examiner un trésor de monnaies et de parures en argent découvert dans la région. Après avoir étudié les monnaies, sans grand succès car il ne put en lire les inscriptions qui n'étaient d'après lui ni en amharique ni en arabe, Traversi se dirigea vers Warkamba en compagnie du gouverneur de Chänno. À une heure de Chänno, il découvrit le site de Ali Ghemb, sur la rive droite de la rivière Awadi, où se situait, lui dit-on, la cité du chérif Ali, fils du fameux Saad Din. Traversi fit une description rapide de la cité (murs d'enceinte, maisons en ruines rappelant celles de Harar, belle mosquée rectangulaire) et signala que la tombe, rectangulaire et faite de 
pierres en tuf, située à gauche de l'Awadi, portait l'inscription suivante : "Questo tomba è del sultano Sceriff-Ali, che Iddio abbia in gloria, morto in un venerdi del 771 del Nebi » (Traversi, 1893 : 682). Dans une seconde lettre, écrite à Addis Abeba le 19 juin 1893, il décrit sa visite à Rassa, une ville ancienne qui daterait de l'époque du Chérif Ali et aurait appartenu à un certain Ras Ali. Traversi mentionne un cimetière, une mosquée où l'on aperçoit encore le mibrab (niche orientée pour la prière), des maisons à un étage, rappelant les constructions de Harar, et les restes d'un mur d'enceinte situé à l'ouest.

Il faut attendre ensuite l'article de Chernet Tilahun publié en 1990 - ce qui en dit long sur le désintérêt longtemps manifesté pour cette zone - pour disposer d'une nouvelle description de quelques sites majeurs de l'Ifat, en particulier Gozé ( $7 \cdot \mathbf{H})$, Rassa Guba ( $\mathbf{G} \mathbf{n - 7}$ ), Asbäri

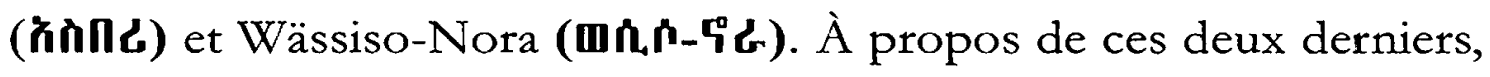
Chernet Tilahun signale le caractère exceptionnel des deux mosquées en ruine qui s'y voient encore, dont il fait une description sommaire et dont il publie quelques photographies. Certains de ces sites ont été à nouveau reconnus et décrits en 2000 par Kebede Geleta (2000). Par ailleurs, nous avons nous-mêmes effectué en 2000 des prospections dans la région de Mafud et réalisé un sondage dans la mosquée en ruine de

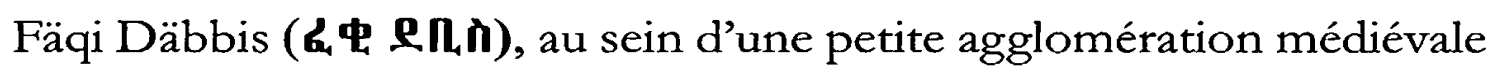
en ruine, qui a livré des datations intéressantes (Hirsch \& FauvelleAymar, 2002 : 321-326). Cette même année, une autre équipe a fait le relevé complet de la mosquée, toujours en usage, de Gozé (Poissonnier et al., 2000).

En 2007, dans la continuité de ce programme, nous avons décidé de poursuivre nos investigations dans la région de Asbäri et Wässiso. Quelles furent les raisons de ce choix ?

Tout d'abord, le signalement de Chernet Tilahun montrait les ruines des deux mosquées les plus impressionnantes et les mieux 
RECONNAISSANCE DE TROIS VILLES MUSULMANES

conservées connues à ce jour en Éthiopie, entourées de ruines d'habitations, ce qui laissait supposer la présence éventuelle de villes médiévales de taille respectable à Asbäri et Wässiso-Nora. D'autre part, notre intérêt se porte depuis longtemps sur la ville médiévale musulmane connue des sources écrites sous le nom Gendebelo ( 739 . In $\boldsymbol{n}^{\circ}$ ) (Hirsch \& Fauvelle-Aymar, 2002 : 330 ; Hirsch \& Fauvelle-Aymar, 2004 : 306310 ), une grande ville commerçante dont nous supposons, à partir de données écrites et orales, qu'elle pourrait se trouver précisément dans cette zone'.

La région où sont localisés les sites d'Asbäri et de Wässiso-Nora (voir relevés $1 \& 2$ ) est située à environ $20 \mathrm{~km}$ au sud-est de la ville de Choa Robit. Il s'agit d'une région de reliefs nord-sud (entre 1300 et $1600 \mathrm{~m}$ d'altitude), sur une longueur de $11 \mathrm{~km}$ environ, qui constitue la bordurc oricntalc d'un palier intermédiaire du Rift avant la descente vers l'Awash. Cette région est aujourd'hui habitée par des Afar, des Argobba et des Amhara, pratiquant l'élevage et l'agriculture et se disputant ce territoire. Les hauteurs où sont situés les sites anciens montrent des traces d'agriculture en terrasse mais sont surtout à l'heure actuelle des zones de pâturage pour les troupeaux. La zone est de nos jours majoritairement musulmane, avec cependant des villages chrétiens sur le plateau et les replats intermédiaires. On remarque que les petits cours d'eau de la région sont rarement pérennes - ce qui explique la présence actuelle de retenues artificielles formées de simples levées de terre. Le climat est de type semi-aride avec une saison sèche accentuée d'octobre à janvier. Les précipitations varient autour de $500 \mathrm{~mm} /$ an et se concentrent de février à avril et surtout de juillet à

${ }^{1}$ La question de cette ville et de sa possible localisation fera l'objet d'un article spécifique. 
François-Xavier FAUVIil. E-AYMAR et al.

septembre. La végétation correspond à une savane arborée avec une strate herbacée dense parsemée d'arbres et d'arbustes épineux.

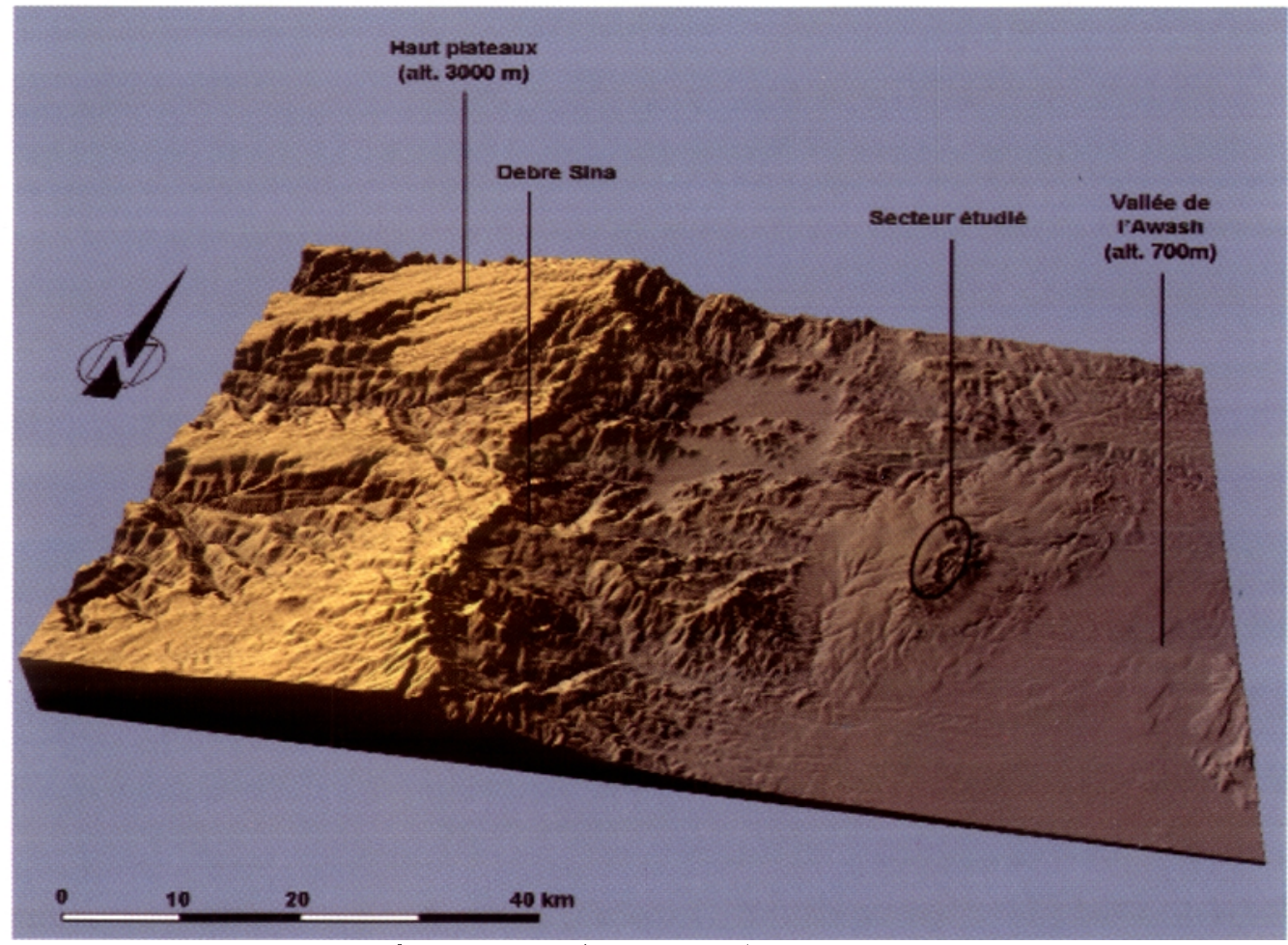

Relevé 1 - Bloc 3D : le platean de l'Awash

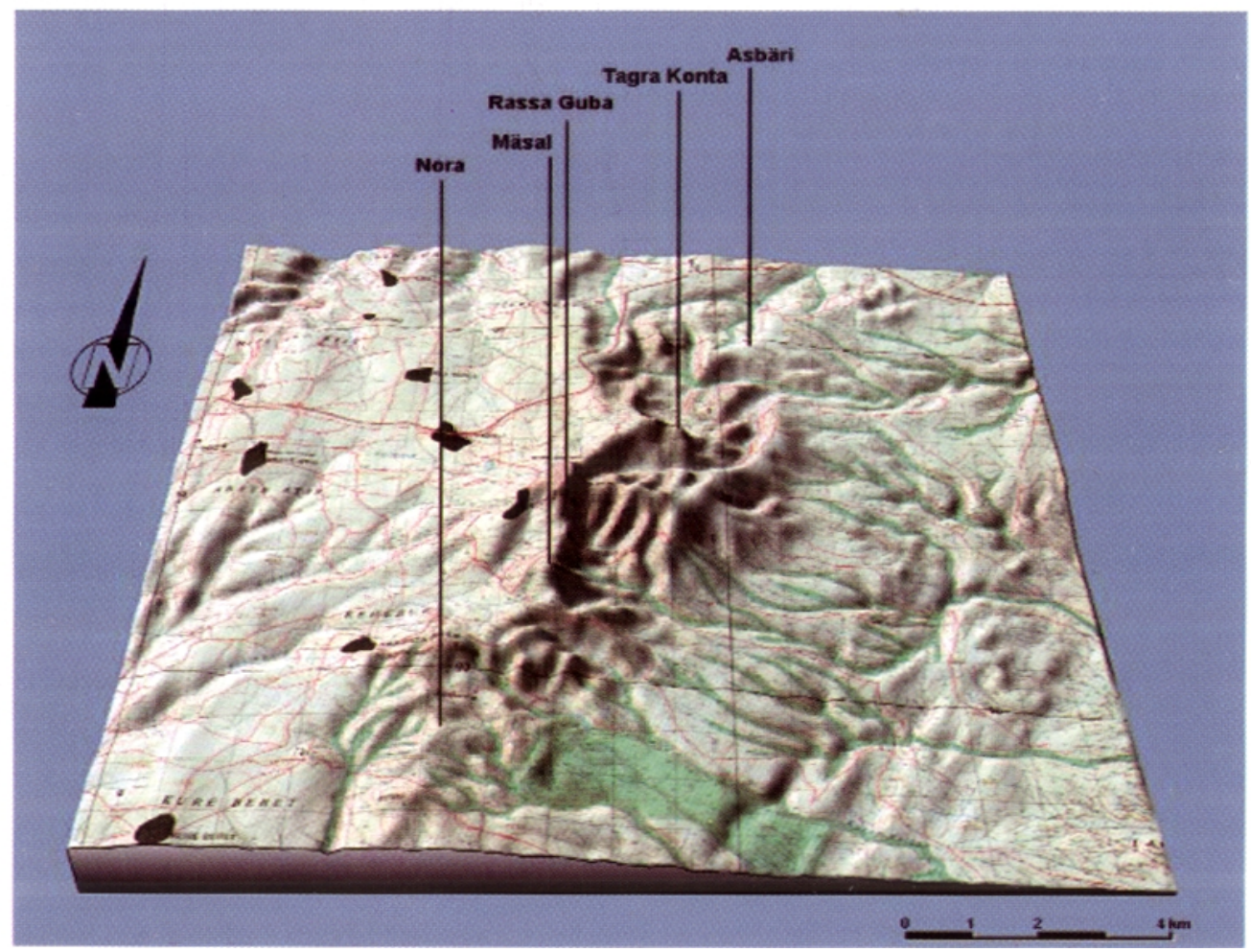

Relevé $2-B l o c 3 D$ : ensemble du secteur étudié 


\section{Le site d'Asbäri}

Situé à $1,5 \mathrm{~km}$ à l'est de la route qui joint les bourgs de Säfi-Bärät

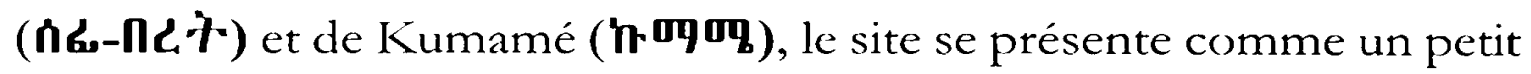
plateau d'une altitude moyenne de $1240 \mathrm{~m}$ et d'une surface de 40 hectares environ.

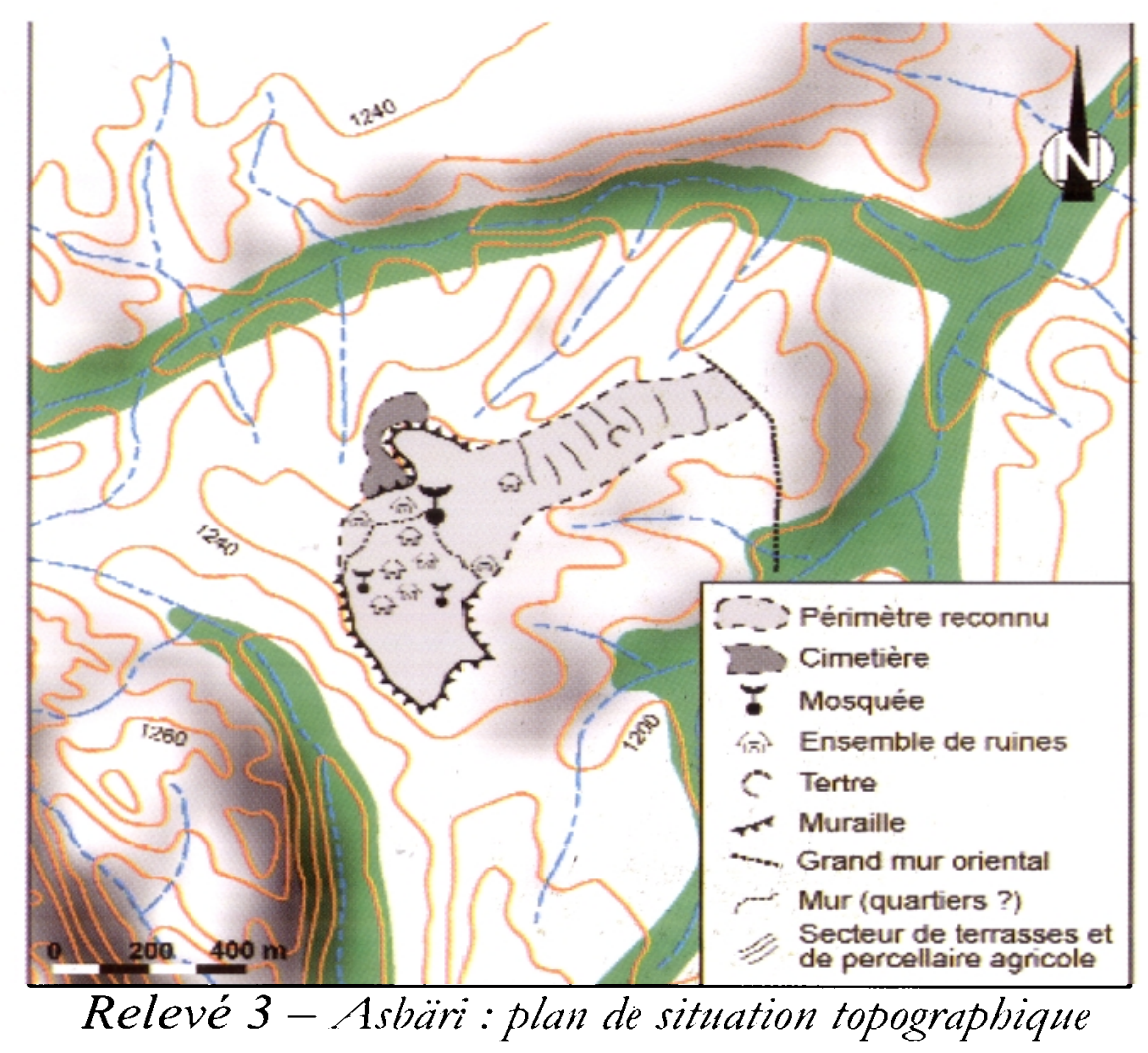

\section{La grande mosquée}

I'élément le plus visible est la présence d'une vaste mosquée en ruines (relevés $4 \& 5$ ), relativement bien conservée, déjà cécrite à plusieurs reprises et qui semble être, dans l'état actuel de nos connaissances, l'une des plus vastes connues sur le territoire éthiopien (voir photo 1). Il s'agit d'un bâtiment rectangulaire avec un mur en blocs jointifs de roches rhyolithiques taillées et appareillées avec soin, présentant un embasement puissant. Ce mur est formé d'un double parement et d'un comblement de blocaille et de mortier. Une ligne régulière de 
blocs rouges sur une partie du périmètre du mur (à environ $1 \mathrm{~m}$ audessus du sol) témoigne du soin apporté au choix des matériaux et à la qualité de la construction.

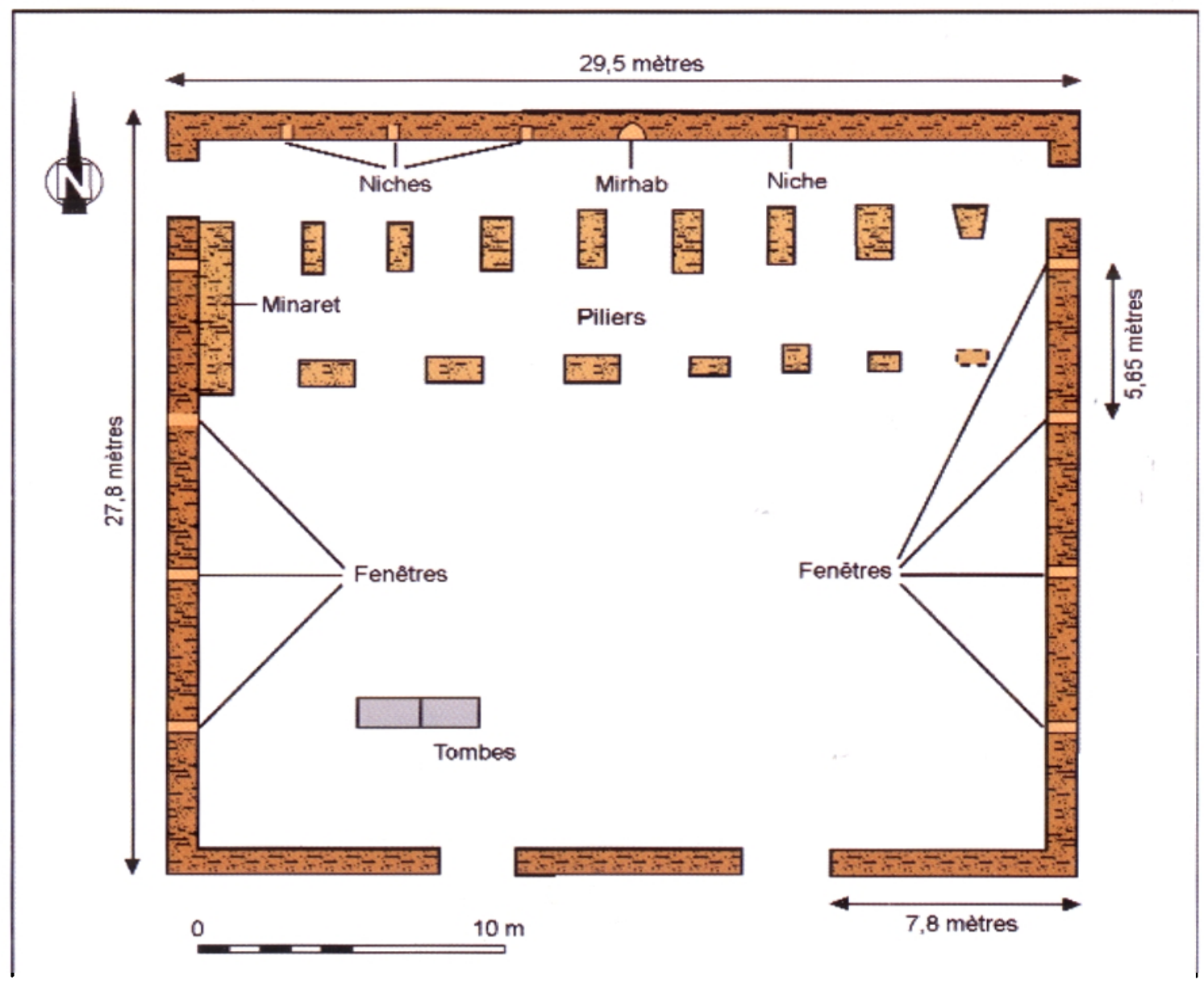

Relevé 4 - Plan de la grande mosquée d'Asbäri

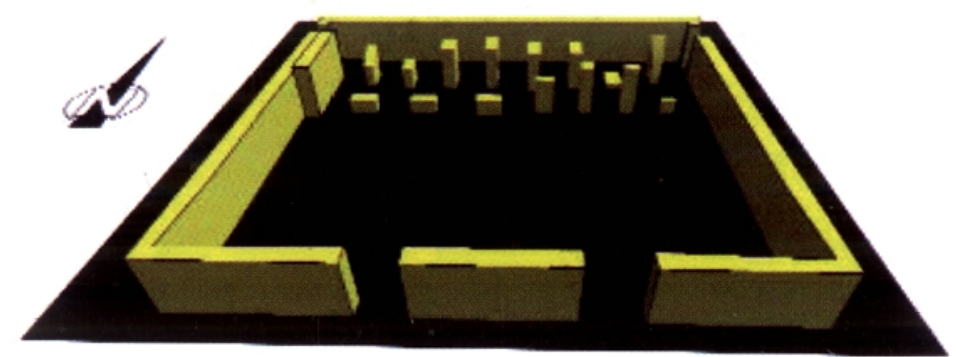

Relevé 5 - Bloc 3D : la grande mosquée d'Asbäri 
RECONNAISSANCE DE TROIS VILLES MUSULMANES

D'une hauteur moyenne de $4 \mathrm{~m}$ et d'une largeur de $1 \mathrm{~m}$, ce mur d'enceinte est endommagé aujourd'hui en quatre points. Le mur nord, qui montre en son centre le mibrab, mesure $29,47 \mathrm{~m}$ de long et contient 4 niches, 3 à l'ouest du mibrab, 1 à l'est (photo 2).

Le mur sud est d'une longueur de 29,11m (soit une trentaine de centimètres de différence avec le mur parallèle) et contient deux brèches qui pourraient correspondre à des portes, hypothèse que l'épaisseur du cône d'effondrement devant chaque ouverture empêche de vérifier sans fouiller. Le mur Est, d'une longueur de $27,87 \mathrm{~m}$, contient 4 fenêtres et une large brèche au nord. Le mur ouest est long de $27,83 \mathrm{~m}$, avec 3 fenêtres et une brèche à l'angle nord. Ces deux autres parties effondrées du mur se trouvent dans les angles nord-est et nordouest, régions où la base du mur est encore bien visible et présente une certaine élévation. Ce fait renforce l'idée que l'une au moins des ouvertures du mur sud a dû correspondre à une porte. L'ouverture de l'angle nord-ouest sert aujourd'hui d'accès aux visiteurs occasionnels du site. Là où le mur a conservé son élévation d'origine, subsistent également quelques dalles de couverture en tuf lité, peut-être destinées à éviter le ruissellement entre les parements. Certaines de ces dalles, tombées vers l'intérieur du bâtiment, ont été réaménagées de façon horizontale à la base du mur. L'existence, dans l'enceinte de la mosquée ou dans ses environs immédiats, de blocs rectangulaires présentant une surface concave hémicylindrique et ressemblant à des segments de gouttière ou de canalisation, pourrait témoigner de l'existence d'un système de collecte ou d'adduction d'eau éventuellement lié à la mosquée (photo 3).

La structure qui vient d'être décrite correspond probablement au mur d'enceinte de la mosquée proprement dite, dont les ruines occupent sur toute sa largeur la moitié nord du quadrilatère formé par le mur. Les aménagements intérieurs de la mosquée présentent un type 
François-Xavier FAUVELLE-AYMAR et al.

différent de bâti, en petit appareil de blocs non taillés ou sommairement équarris, généralement de tuf, joints par un mortier de bonne qualité, mais scellant un bâti qui a moins bien résisté au temps que celui de l'enceinte. Un tell d'effondrement de près d'un mètre signale que la mosquée devait être couverte dans cette partie. De cette structure, seuls subsistent les piliers massifs, de section rectangulaire : une première rangée, parallèle au mur de la qibla, montre un alignement de 8 piliers rectangulaires orientés au nord, d'environ $0,90 \mathrm{~m}$ sur $2 \mathrm{~m}$ de base pour une hauteur variant de 2 à $4 \mathrm{~m}$. Une seconde rangée, séparée de la première par environ $1,50 \mathrm{~m}$, contient 7 piliers (le plus à l'est étant complètement effondré) avec une base de taille variable (longueur de $0,85 \mathrm{~m}$ à $1,80 \mathrm{~m}$, largeur de $0,68 \mathrm{~m}$ à $1 \mathrm{~m}$ ), orientés est-ouest. En quelques endroits, des restes de murs en même appareil viennent s'appuyer sur les piliers (photo 4).

Cet espace couvert et partiellement fermé formait le lieu de prière de la mosquée sur une surface d'environ $330 \mathrm{~m}^{2}$.

On remarque à l'ouest de cet espace un mur intérieur qui n'est pas appliqué contre le mur d'enceinte, mais séparé de lui par un espace partiellement comblé, à l'intérieur duquel se trouvait probablement l'escalier d'accès au minaret (photo 5), s'il faut se fier à l'exemple de la mosquée de Nora ( $\mathbf{5}$ '). La partie effondrée, en bas de ce mur, ne peut absolument pas être identifiée, comme le fait Chernet Tilahun, à un second mibrab (Chernet Tilahun, 1990 : 308). L'espace extérieur au sud du bâti formait probablement une cour (surface de $480 \mathrm{~m}^{2}$ ). On y remarque aujourd'hui, au sud-ouest, la présence de deux tombes rectangulaires. Sur certaines pierres, à l'intérieur et surtout à l'extérieur du mur d'enceinte, on note la présence de trois types d'inscription : des tablettes de lecture sont figurées, dont une en relief sur le mur de la qibla (photos 6), peut-être conçue dès la construction de la mosquée, et d'autres, plus sommaires, gravées sur les pierres extérieures du mur 


\section{RECONNAISSANCE DE TROIS VIILIES MUSULMANES}

d'enceinte. Une inscription ancienne, en relief, a été également relevée sur une pierre extérieure du mur ouest, vers l'angle sud (photo 7). Plusieurs autres inscriptions arabes gravées ont été repérées sur le mur intérieur est. Par ailleurs, on note la présence de nombreux graffitis essentiellement sur le mur d'enceinte extérieur: des étoiles, des traits verticaux, des séries de trous...

\section{Autres établissements religieux}

Outre la grande mosquée, plusieurs autres bâtiments cultuels avec mibrab, petites mosquées, oratoires ou zaniya, sont également repérables sur le site.

La première, de forme rectangulaire, se situe à $250 \mathrm{~m}$ au sud-ouest de la mosquée principale (photo 8). Le bâti montre le même type de construction que celui utilisé pour la grande mosquée - on remarque en particulier une même ligne de pierres rouges sur le mur d'enceinte -, avec cependant un appareillage moins régulier et l'utilisation de pierres de moindre module.

Le mur nord, d'une longueur de $10,20 \mathrm{~m}$ est relativement bien conservé et laisse encore apparaître trois niches, deux à l'est et l'une à ouest, de ce qui semble avoir été le mibrab, actucllement recouvert d'un amas de terre et que seule une fouille permettrait éventuellement de mettre au jour. Le mur Est, presque intégralement détruit sauf au niveau des deux angles formés avec les murs nord et sud, mesure 10,70m. Le mur sud est effondré au niveau de la porte. Le linteau en pierre repose encore sur le sol. Une niche se situe sur le côté ouest de la porte. À cet endroit, le mur atteint $3,30 \mathrm{~m}$ de hauteur et $0,80 \mathrm{~m}$ de largeur. Le mur ouest, d'une longueur de $10,65 \mathrm{~m}$, est le mieux conservé et est percé de deux fenêtres.

La seconde petite mosquée ou oratoire est située à $260 \mathrm{~m}$ au sud de 
François-Xavier FAUVELLE-AYMAR et al.

la mosquée principale. De forme carrée, les murs mesurent $6,60 \mathrm{~m}$ de côté et sont construits suivant la même technique, mais avec moins de soin. Le mur nord est le mieux conservé. Le mibrab est entièrement visible (photo 9) et entouré de quatre niches, deux de chaque côté.

Le mur atteint une hauteur de 2,30m et une largeur de $0,70 \mathrm{~m}$. Les trois autres murs sont presque intégralement effondrés. L'intérieur de cette mosquée est comblé par des amas de terre et de pierres.

Sur un éperon rocheux surplombant le site d'Asbäri, à environ $1,5 \mathrm{~km}$ au sud-ouest, que l'on ne peut atteindre que par une ascension difficile, se trouvent les restes très endommagés de ce qui fut vraisemblablement une petite mosquée ou zawiya. Le site porte aujourd'hui le

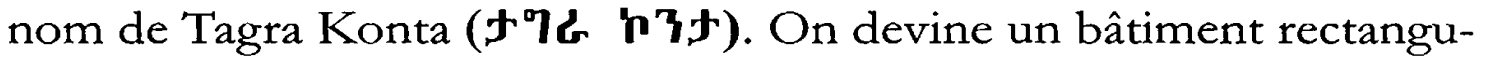
laire (largeur d'environ 9,50m pour une longueur supérieure à $11 \mathrm{~m}$ ). Seule une portion du mur ouest montre encore une élévation d'environ $1 \mathrm{~m}$ et quelques bases d'angles restent visibles ainsi que quelques graffitis sur des pierres des ruines du mur ouest. On peut supposer que cet établissement religieux était en relation avec le site d'Asbäri.

\section{Le cimetière}

Un cimetière de plusieurs centaines de tombes longe tout le flanc nord de la colline où se situe la mosquée ; deux murs d'enceinte en délimitent l'extrémité est et nord. Le cimetière occupe une surface considérable de près d'un hectare. Les tombes (photo 10) ne sont pas disposées de manière ordonnée, les orientations varient. Les tombes sont de forme variables : carrées, rectangulaires et même rondes. Nombre d'entre elles ont une pierre en leur centre. La prospection a permis de repérer une forte concentration de céramiques (anses, tessons...) ainsi que des meules. 
RECONNAISSANCE DE TROIS VILLES MUSULMANES

\section{La ville}

Les ruines d'Asbäri occupent un vaste replat topographique isolé par plusieurs petites vallées profondes d'une cinquantaine de mètres. Sa partie sud, ainsi que celle dominant le cimetière au nord est clairement barrée par une muraille sise sur la rupture de pente.

À l'est du site, très en retrait par rapport aux dernières constructions visibles, un mur rectiligne orienté nord-sud, de $2 \mathrm{~m}$ d'épaisseur et d'une élévation d'au moins $1 \mathrm{~m}$ barre entièrement l'accès depuis le plateau sur plusieurs kilomètres de longueur, mais le type de bâti (une simple accumulation de pierres) et le moindre délabrement apparent de la structure fait peser des doutes sur son caractère contemporain ou non au site (photo 11).

Entre ce mur et le site proprement dit, une vaste zone inclinée présente des restes de terrassement et/ou de parcellaire, avec peu d'autres traces de culture matérielle que de nombreux fragments de meules en basalte. Cette zone, aujourd'hui reconquise par la végétation arbustive, pourrait avoir été, à l'époque d'Asbäri ou postérieurement à sa ruine, le site d'implantation d'une population d'agriculteurs.

Les ruines d'Asbäri présentent, autant qu'il est possible d'en juger par une simple prospection, un aspect généralement clairsemé, quoique certaines zones de plus grande densité laissent deviner un habitat plus serré et, parfois, à proximité de la muraille, l'apparence de rues ou du moins de voies d'accès. Les restes de murs visibles présentent une faible élévation, et les structures ne sont le plus souvent repérables qu'aux tells qu'elles ont formés. Au moins deux longs murs continus, convergents vers la mosquée, semblent délimiter des quartiers.

La prospection révèle de très nombreux tessons de poterie, dont les formes rappellent celles de la céramique actuelle pour ce qui est des tessons les plus robustes (fragments de grande jarres à eau identifiable 
aux anses), mais aussi de la céramique médiévales du Tchertcher

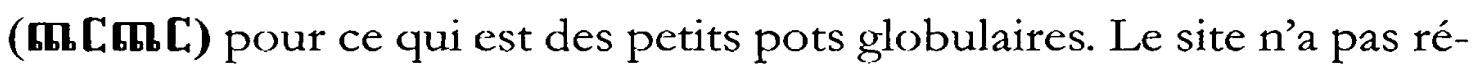
vélé d'outils en obsidienne.

\section{Les sites de Mäsal (四內), Rassa Guba et Hajji Mänsur ( on 3itc)}

Sur la même ligne de reliefs où se dressent les sites d'Asbäri au nord et de Wässiso-Nora au Sud, on trouve à l'est du village actuel de Kedä Bura (h) $\mathbf{T} \boldsymbol{G}$ ) un ensemble significatif d'au moins trois sites musulmans médiévaux.

\section{Mäsal}

Situé à 1,5km de Kedä Bura, le site de Mäsal (relevé 6) est localisé au sommet d'un relief atteignant $1500 \mathrm{~m}$ d'altitude. Il forme un replat morphologique d'une dizaine d'hectares au maximum. Les limites ouest et nord sont constituées par des versants en forte pente qui dominent la plaine de plus d'une centaine de mètres. Toute la partie orientale du replat est bordée par des corniches vertigineuses qui surplombent le palier inférieur du Rift. 
RECONNAISSANCE DE TROIS VILLES MUSULMANES

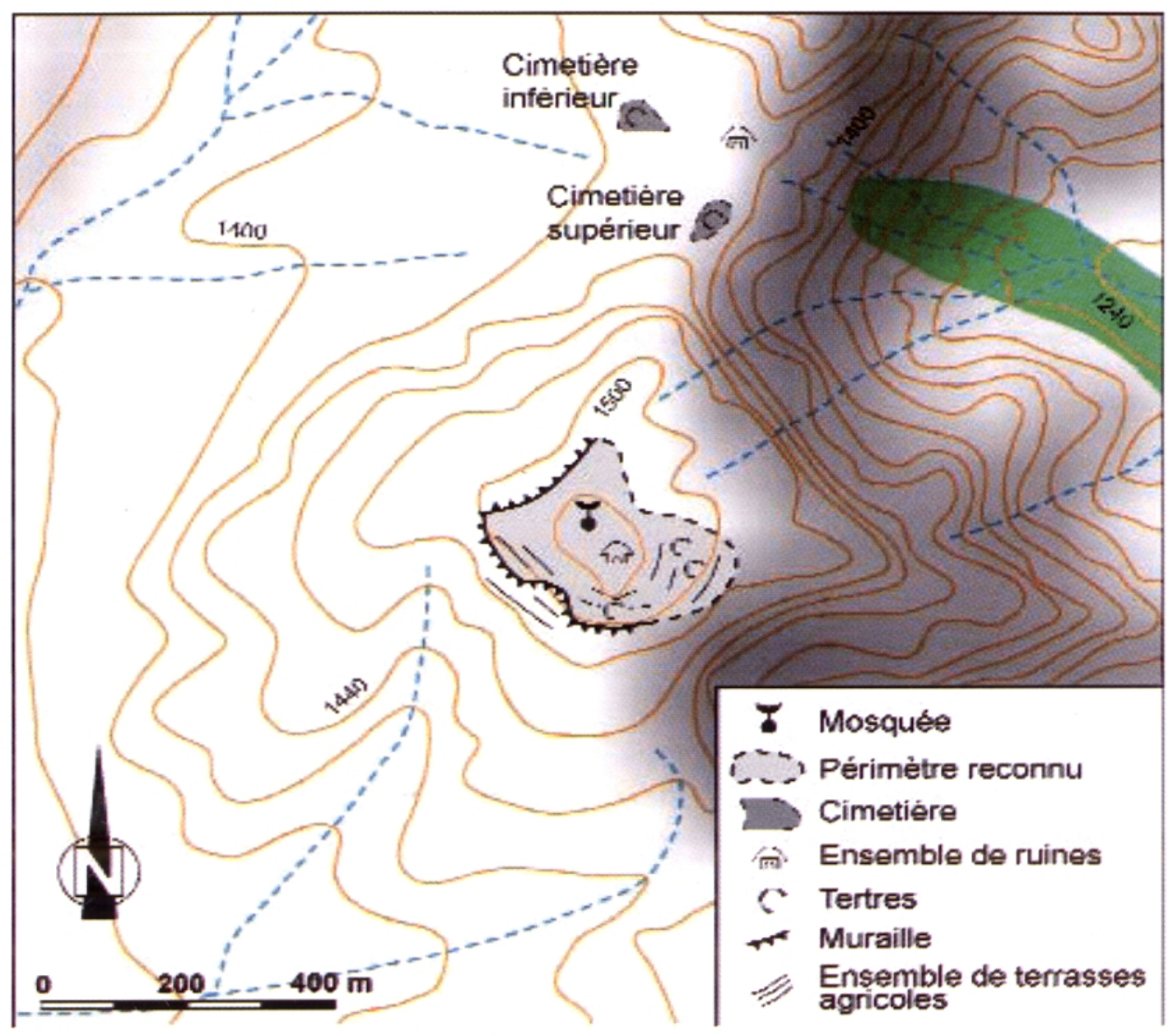

Relevé 6-Mäsal : situation topographique

\section{Les cimetières de Mäsal}

On remarque d'abord, au pied du versant nord-ouest de ce relief, une vaste zone de tombes musulmanes, orientées $\mathrm{E}-\mathrm{W}$, avec la présence d'au moins un tumulus (cimetière inférieur). Ces tombes, en assez mauvais état, sont de plusieurs types : type 1 , rectangulaires et formées de quatre blocs taillés, de plus ou moins belle facture (photo 12) ; type 2, identique au précédent, mais avec un cercle de pierre autour de la tombe rectangulaire (photo 13); type 3, de forme carrée (photo 14); type 4 , unique : cercle de pierres avec un bloc monolithe sculpté au centre (photo 15). Un nombreux matériel de surface (tessons, obsidienne) parsème la surface du site. 


\section{François-Xavier FAUvelLe-Aymar et al.}

Un peu plus haut, en position de col topographique, se trouve un exceptionnel cimetière musulman (cimetière supérieur). Il se compose de deux espaces : sur l'espace le plus haut, le cimetière ancien, auquel a été adjoint au nord un cimetière plus récent. Chacun de ces espaces est délimité par un mur dont on peut suivre encore aujourd'hui le tracé, malgré le manque actuel d'élévation.

Le cimetière ancien se développe sur une surface de $1200 \mathrm{~m}^{2}$ (photo 16). À l'intérieur, on observe une série de tombes alignées en bandes parallèles, orientées E-W et le plus souvent formées de 4 blocs de pierres bien taillés. On compte environ 230 tombes. Ces pierres ne portent pas d'inscriptions, à l'exception de rares dessins rectangulaires incisés (tablettes de lecture ?) (photo 17). À titre d'exemple, deux tombes anciennes présentent les dimensions suivantes : longueur $140 \mathrm{~cm}$, largeur $85 \mathrm{~cm}$, hauteur $24-25 \mathrm{~cm}$, épaisseur $15-16 \mathrm{~cm}$; longueur $150 \mathrm{~cm}$, largeur $84 \mathrm{~cm}$, hauteur $25-33 \mathrm{~cm}$, épaisseur $12-18 \mathrm{~cm}$. Les habitants de Kedä Bura disent qu'il s'agit de tombes d'« Arabes ».

Nous avons relevé la présence de trois tumulus dans l'enceinte même du cimetière ancien. Un mur d'enceinte plus ou moins bien conservé de forme quadrangulaire entoure ce premier cimetière. Le mur Est, d'une longueur de 46,5m, longe la corniche. Le mur nord, long de $30,10 \mathrm{~m}$, sépare le cimetière ancien du plus récent. Un tumulus s'appuie sur le mur ouest, le mieux conservé et qui mesure $45,8 \mathrm{~m}$. Le plus grand tumulus du cimetière longe presque intégralement le mur $\operatorname{sud}(12,46 \mathrm{~m})$.

Le cimetière plus récent est entouré d'un mur d'enceinte qui s'ajoute à l'ancien. Il contient quelques tombes anciennes ainsi que des tombes récentes qui se présentent comme des parallélépipèdes d'une hauteur moyenne de $50 \mathrm{~cm}$ entourés de pierres. Certaines tombes ont été récemment entourées d'un petit mur d'enceinte pour les protéger. 
RECONNAISSANCE DE TROIS VILLES MUSUIMMANES

\section{La mosquée et le site urbain de Mäsal}

À $500 \mathrm{~m}$ au SSW du cimetière et à une centaine de mètres en contre-haut se dressent les ruines d'une mosquée. Les habitants de

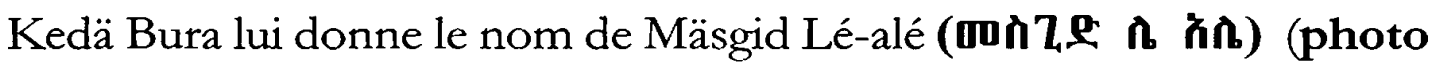
18).

Cette mosquée, en moins bon état que celle d'Asbäri et d'une facture plus grossière, est construite sur le même plan que les précédentes. Le mur nord, où l'on reconnaît le mibrab au centre, mesure $15,55 \mathrm{~m}$ de long, est effondré sur toute sa partie centrale ; il comporte deux niches, de part et d'autre du mibrab. Ce mur avec double parement mesure $1,30 \mathrm{~m}$ de largeur et atteint dans l'endroit le mieux conservé une hauteur de 2,05m. Le mur ouest, le mieux conservé (longueur 12,30m, hauteur maximale relevée de $2,80 \mathrm{~m}$ ) est percé de trois fenêtres. Le mur sud, détruit dans sa portion centrale (où devait se situer la porte d'entrée) qui a été rebouchée grossièrement, mesure 13,50m de long pour une largeur de $0,75 \mathrm{~m}$. Le mur Est, fortement endommagé, mesure $12,30 \mathrm{~m}$ de long et est percé de trois fenêtres. On remarque l'absence de traces de piliers à l'intérieur du mur d'enceinte.

Autour de la mosquée, on peut repérer plusieurs traces d'aménagements. Ainsi, une muraille d'enceinte peut se suivre sur plus de $500 \mathrm{~m}$, le long des versants sud et ouest. Le versant Est, quant à lui, présente des traces d'habitations en ruine et des tumulus. Enfin, des terrasses agricoles occupent les versants est, sud et ouest. Dans ce dernier secteur, les terrasses se développent même au-delà de la muraille.

\section{La mosquée de Rassa Guba}

À l'est de Kedä Bura, à un peu moins de $2 \mathrm{~km}$ de Mäsal, on atteint les ruines d'une petite mosquée ou d'un oratoire. Elle se situe non loin du sommet d'une série de collines qui dépassent $1660 \mathrm{~m}$ d'altitude. 
François-Xavier FALVELLE-AyMAR et al.

Cette mosquée, du nom de Rassa Guba (relevé 7), est située sur une crête étroite qui se termine par un éperon rocheux dominant à l'ouest le plateau d'Abaye Atir et à l'est le pallier inférieur du Rift (photo 19).

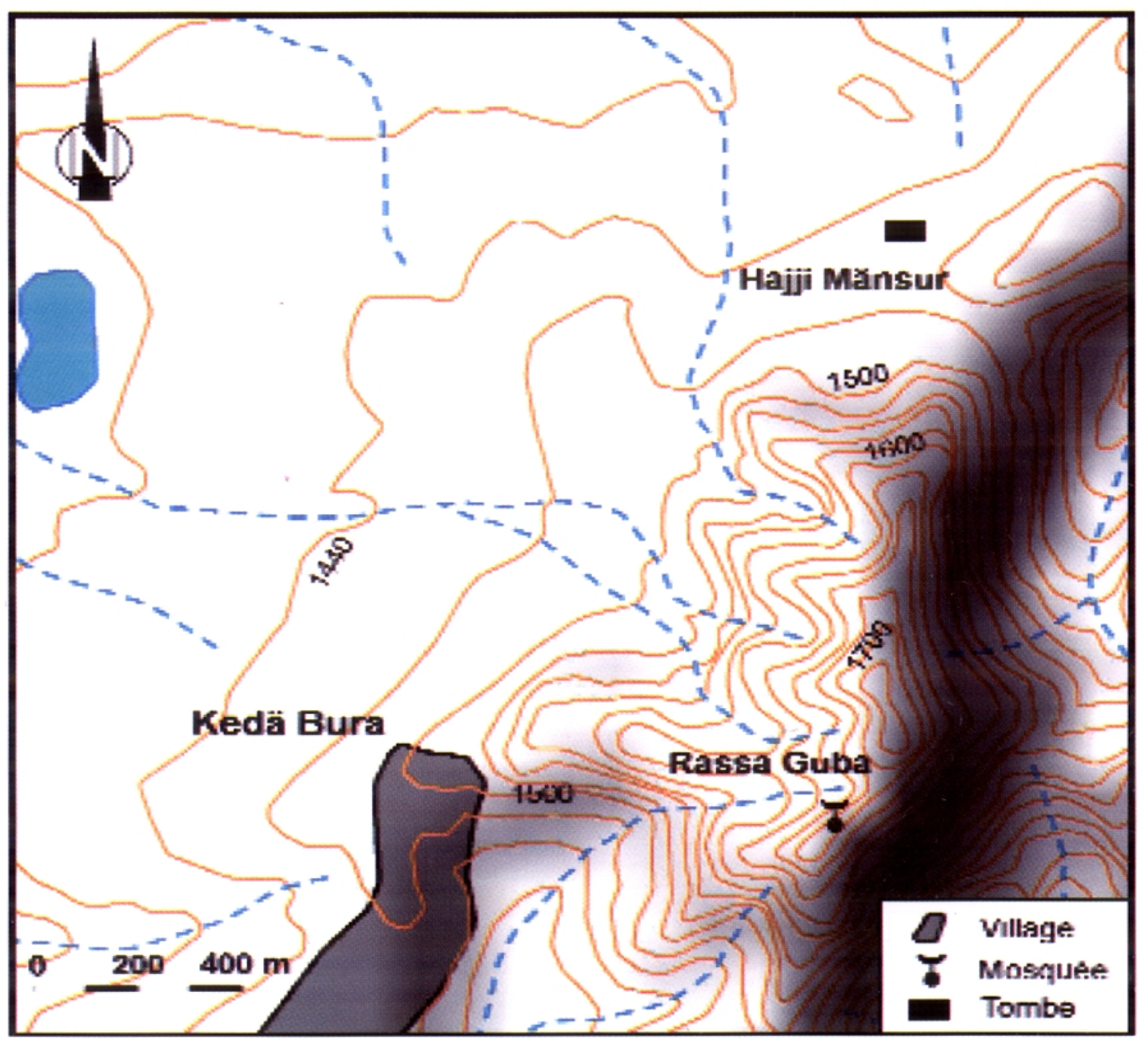

Relevé 7 - Rassa Guba et Hajji Mänsur : situation topographique

Il s'agit d'un bâtiment en pierre, probablement rectangulaire et de petite taille, dont il ne reste actuellement que le mur nord dans son entier, où l'on peut deviner la base du mibrab et repérer au moins une niche et une partie du mur ouest (mur nord : $7 \mathrm{~m}$ de long, mur ouest : $5,42 \mathrm{~m}$; hauteur maximale relevée : $3,45 \mathrm{~m}$ ) avec deux fenêtres et une niche. On note la présence probable de puits autour de la mosquée.

Au NNE de la mosquée, de l'autre côté du sommet, et à une dis- 
tance de $350 \mathrm{~m}$, se remarque une structure circulaire en pierre, près d'un long mur d'enceinte (peut-être récent) qui longe la corniche et l'on trouve au sol de nombreux tessons de céramiques.

\section{Le cimetière de Hajji Mänsur}

À 1,5km au nord de Kedä Bura, au pied du versant ouest des reliefs (1440m d'altitude), s'étend un vaste cimetière musulman, toujours utilisé et appelé par les habitants du nom de Hajji Mänsur. On y trouve des tombes surtout récentes, mais aussi quelques tombes du type de celle du cimetière ancien de Mäsal et une tombe tout à fait exceptionnelle, déjà décrite par Chernet Tilahun (1990 : 310 et fig. 4) (photo 20). Il s'agit d'un quadrant de pierre parallélépipédique monolithe, qui porte sur ses quatre faces des cartouches avec des inscriptions en arabe. Sur les quatre coins supérieurs sont gravées des étoiles de Salomon $(13 \mathrm{~cm}$ de diamètre) (photo 21). Cette tombe, avec deux autres tombes adjacentes faites de quatre blocs, est actuellement protégée par un mur d'enceinte récent. Elle est brisée à trois endroits. Ce monument, orienté $\mathrm{E}-\mathrm{W}$, est d'une hauteur visible de $22 \mathrm{~cm}$. La face nord mesure $1,47 \mathrm{~m}$, la face Est $0,63 \mathrm{~m}$, la face sud $1,51 \mathrm{~m}$ et la face ouest $0,68 \mathrm{~m}$.

L'inscription a été partiellement déchiffrée dans l'article de Tchernet Tilahun (1990:ibid), qui propose la traduction suivante pour la face sud : "There is no God except Allah and Mehammed is the messenger of Allah » et « Rais Ali - King and the son of King let Allah be mercy upon him " pour la face nord. Selon Ato Ebnayetu Allo, un Afar, interrogé le 8 janvier 2007 et qui tient ses informations d'amis argobba, cette tombe aurait été déterrée par des chercheurs des trésors en 1943/1944. Selon lui, les gens creusèrent cette tombe après avoir fait déchiffrer les inscriptions arabes qui auraient signalé la présence d'or dans la sépulture. Mais le mort aurait parlé aux chercheurs de trésors 
François-Xavier FALvisilı-AYMMAR et al.

en leur disant : "Pourquoi me décevez-vous ? ». Terrifiés par ces paroles, les pilleurs auraient fuit pour toujours sans avoir rien découvert.

Ce cimetière, d'après les habitants interrogés, ne semble pas connecté avec un site ancien proche.

\section{Le site de Nora-Wäsisso}

I.e site de Nora (relevé 8) est localisé sur un relief tabulaire isolé par les entailles du réseau hydrographique, à $45 \mathrm{mn}$ de marche du village argobba de Wäsisso. De nombreuses ruines, présentant parfois une élévation jusqu'à un à deux mètres, révèlent un habitat urbain dense ainsi qu'un réseau de ruelles livrant ici ou là des restes de pavement. I Le site livre également une grande mosquée et une nécropole.

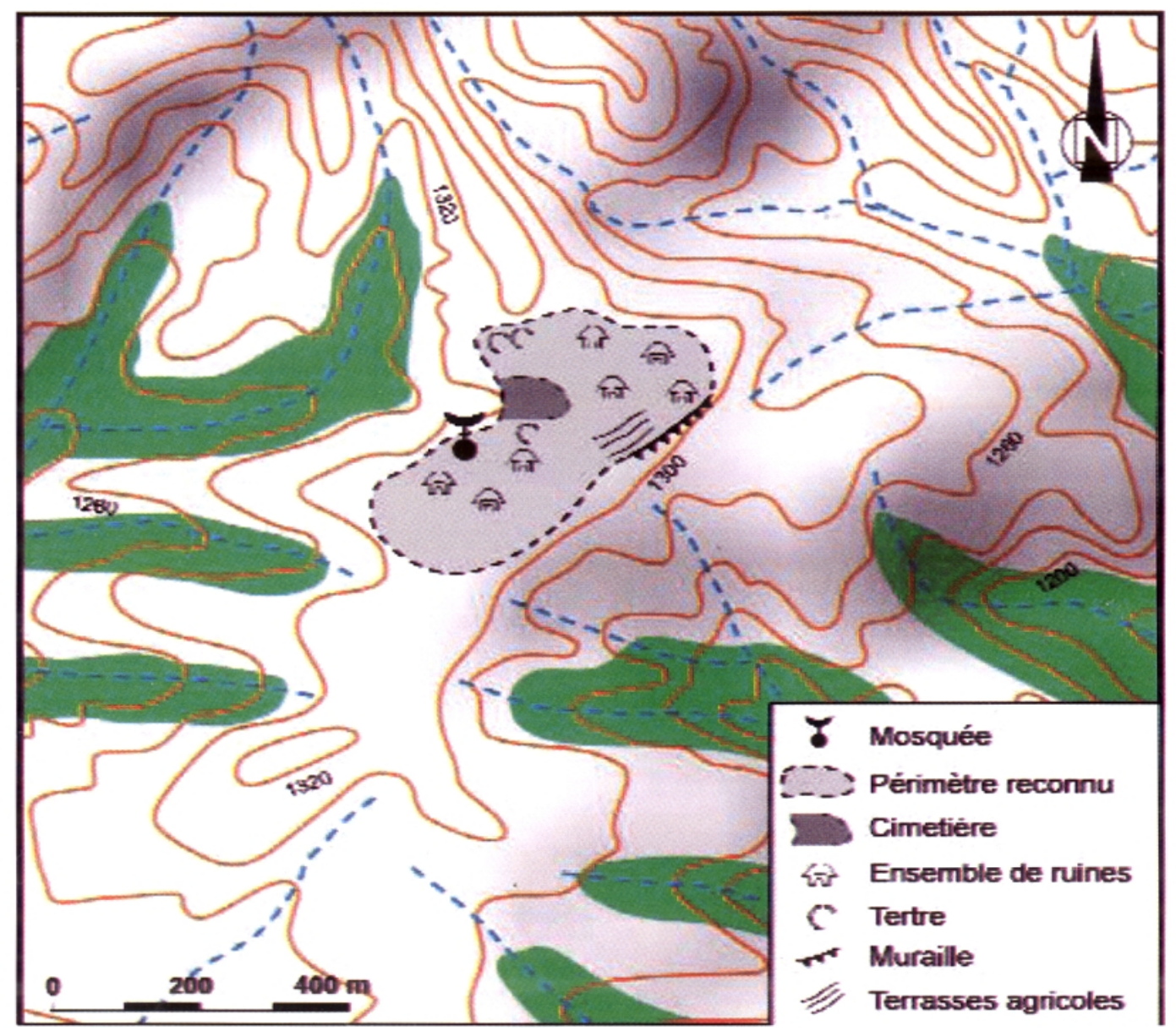

Relevé 8 - Nora : situation topographique 
RECONNAISSANCE DE TROIS VILLES MUSULMANES

\section{La ville}

Les bâtiments, vraisemblablement d'habitation, sont distinctivement de plan quadrangulaire, réminiscence des habitations traditionnelles argobba ou harari : le mur faisant face à la porte d'entrée, dans les cas où l'élévation est suffisante pour en juger, présente deux niches carrées placées de part et d'autre de façon symétrique, tandis que la surface au sol devant ce mur de fond, plus élevée que sur le devant de l'habitation, pourrait révéler l'aménagement d'une large banquette. À une centaine de mètres au sud-est de la mosquée, une ruine d'habitation semble bien plus vaste que les autres avec apparemment plusieurs pièces (photo 22).

L'organisation des espaces d'habitat et des espaces emmurés formant des cours ou des enclos domestiques est difficilement lisible. Les rues en paliers aménagés sont d'autant plus apparentes le long de leurs segments situés au pourtour de la zone urbanisée, à proximité immédiate dc la muraille, ouvrant sur des portes. Certaines de ces rues sont longées de part et d'autre de murs dans le même appareil que les ruines d'habitations (photo 23).

La muraille est aménagée en gros blocs sur la ligne de rupture de pente de l'éperon, à l'endroit où l'affleurement du substrat forme un rempart vertical naturel de plusieurs mètres de hauteur. Plusieurs ruines circulaires sont disposées le long du périmètre intérieur de la ville (photo 24).

\section{La mosquée}

La mosquée de Nora (photo 25), située au point le plus élevé du site, à une altitude de $1306 \mathrm{~m}$, suit un plan rectangulaire de $13,20 \mathrm{~m}$ de long et de $12,20 \mathrm{~m}$ de large. Les murs ont environ $5 \mathrm{~m}$ d'élévation. La porte d'entrée (photo 26), large de 0,75m et composée de deux lin- 
teaux superposés, l'un en bois, l'autre en pierre, fait face au mur de la qibla, au nord. Les murs latéraux présentent chacun trois fenêtres disposées de façon symétrique en vis-à-vis ; les fenêtres du mur ouest ont été obturées ainsi que la fenêtre centrale du mur est. Une niche est aménagée à gauche du mibrab dans le mur nord.

Dans l'angle nord-est de la mosquée, derrière l'unique pilier subsistant (de section circulaire), est aménagée au niveau du sol un passage étroit dans le mur, qui a été pris par Chernet Tilahun (1990:308) pour l'entrée d'une chambre secrète (photo 27). Il s'agit en réalité de l'accès à un escalier montant aménagé entre le mur de la mosquée et une structure de $8 \mathrm{~m}$ de long et de $1,60 \mathrm{~m}$ de large s'appuyant contre le parement extérieur nord du bâtiment. De toute évidence, cette structure est ce qui subsiste d'un minaret, aujourd'hui ruiné pour la partie initialement située au-dessus du niveau de la terrasse à laquelle on peut encore accéder (photo 28).

\section{La nécropole}

Au niveau d'un col, non loin de la mosquée, des dizaines de sépultures musulmanes sont plus ou moins bien préservées (photo 29). Le replat, très érodé vers l'ouest, verse dans un ravin avoisinant, où se trouvent encore plusieurs dizaines de tombes, dont il est difficile de savoir si elles sont in situ ou perturbées.

L'ensemble du site livre en très grand nombre des outils d'obsidienne, généralement des grattoirs discoïdes ou des nucleus, ainsi que des tessons de céramique à dégraissant minéral, épaisse $(1 \mathrm{~cm})$, bien cuite. La céramique est particulièrement abondante sur un grand tell situé à environ $200 \mathrm{~m}$ au nord-est de la mosquée, en périphérie de la nécropole et à une altitude de $1302 \mathrm{~m}$. La localisation de ce tell, sa morphologie et l'hypothèse d'un reste de parement à la base, ainsi que 
RECONNAISSANCE DE TROIS VILLES MUSULMANES

l'abondance de céramique, fait penser à un tumulus.

Au moins deux autres possibles tumulus ont été identifiés dans l'enceinte de la ville, tous à proximité de la nécropole. L'un deux, démonté, laisse visible la cella formée d'une dalle horizontale perpendiculaire à la pente sur deux murs de blocs latéraux, figure typique des monuments funéraires médiévaux du Tchertcher.

À partir des premières données recueillies durant cette mission de prospection, plusieurs éléments méritent d'être commentés plus en détail et posent de nouvelles questions à l'historien.

\section{Cités musulmanes : de nouvelles hypothèses}

L'un des acquis majeurs de cette prospection est de pouvoir révéler l'existence de trois véritables sites urbains d'importance (Asbäri, Mäsal, Nora) sur un territoire assez restreint (remarquons que l'on ne connait pas d'autres ensembles du même type, au moins dans la région de l'Ifat). Ces villes devaient entretenir d'étroites relations entre elles, si l'on suppose, ce qui n'est pas acquis avant des recherches archéologiques plus poussées, qu'elles furent (au moins partiellement) contemporaines.

Notons qu'aucun indice ne permet pour l'instant de connaître la date de destruction ou d'abandon de ces sites ; à l'exemple de Gendebelo, ville connue par les textes, partiellement détruite par les troupes de l'imam Ahmed Grañ et dont rien ne laisse supposer l'existence continue après cet épisode, on peut proposer sous toute réserve d'attribuer au XVI ${ }^{\text {e }}$ siècle le terminus post quem de ces sites urbains.

En tout cas, ces sites offrent d'évidents points communs : la présence d'une ou plusieurs mosquées au sein de la ville; l'existence de murailles encerclant l'espace urbain proprement dit - fait non reconnu 
François-Xavier FAUVelle-Aymar et al.

jusqu'à aujourd'hui (probablement parce que l'on a accordé trop de crédit à la formule d'al-'Umari sur les cités du « pays de Zeyla » [l'Ifat] : «les villes n'ont point de murailles et l'architecture n'y a aucune splendeur »; Gaudefroy-Demombynes, 1927 : 4) ; une assez forte densité de ruines d'habitations domestiques en pierre et de tessons de céramique, très abondants dans certaines zones ; la présence possible de puits qui permettaient, dans une zone où les petits cours d'eau ne sont pas pérennes, d'atteindre les nappes phréatiques et donc de rendre possible une occupation humaine durable; l'existence de vastes cimetières en bordure des cités ; et enfin, dans les trois cas, des traces de terrassements agricoles montrant que les abords immédiats de ces villes étaient très probablement cultivés.

Il faut aussi signaler quelques différences notables entre ces sites : d'abord leur état de conservation variable, l'ensemble urbain de Nora étant mieux conservé que celui d'Asbäri, dont le site a été remployé en cultures jusqu'à une période récente et où les pierres ont été souvent réutilisées pour bâtir de petites structures contemporaines. Cela rend pour l'instant assez difficile la comparaison des structures d'habitation, même si certaines structures subsistant à Asbäri comme à Nora montrent des similitudes frappantes (construction rectangulaires en roches rhyolitiques, du même type que celle utilisées pour les mosquées, avec des niches dans les murs, ce qui n'est pas sans rappeler certains types d'habitations actuelles ou sub-actuelles d'Éthiopie). D'autre part, la taille des trois sites est différente : 40 ha pour Asbäri, 10 pour Nora, 6 pour Mäsal. Enfin, il semble y avoir des variations dans le matériel observé en surface : abondance par exemple d'obsidienne à Nora et Mäsal, très peu présente à Asbäri, présence plus évidente de tumulus funéraires à Nora et Mäsal. Il n'en reste pas moins que seule une étude plus approfondie de ces sites, de leur plan, des structures d'habitat et du matériel archéologique qui y est conservé nous permettra d'aller 
au-delà de ces constatations sommaires.

A-t-on quelque chance, dans l'état actuel, d'identifier ces villes à l'une ou l'autre de celles qui sont connues par les sources écrites médiévales?

La toponymie actuelle ne peut être que d'une faible utilité. Les noms semblent assez récents et, surtout, varient selon les populations. Par exemple, le site de Rassa Guba est nommé ainsi par les amarophones mais est appelé Kedä Bura par les afarophones. Ces variations onomastiques révèlent par ailleurs une vive concurrence actuelle des mémoires autour de ces sites et de leur territoire, revendiqués à la fois par les Afar et par les Argobba. L'accord se fait, en apparence du moins, pour éviter des conflits trop voyants, en attribuant la fondation de ces villes, de leurs mosquées et des cimetières à des étrangers, des "Arabes ». C'est ainsi que nous avons récolté un intéressant récit rapporté par un vieillard de Kedä Burra, Ato Ebnayetu Allo, âgé de 75 ans, Afar d'origine, qui affirme tenir ses connaissances sur ces villes anciennes d'amis argobba rencontré à Harar et à Djibouti. Selon lui, avant l'arrivée des Afar dans la région, ce sont des Arabes émigrés qui ont bâti ces villes maintenant ruinées. Les premiers à venir sur la terre des Habäsha (Nuh) et à construire ces villes auraient été des Beni Has-

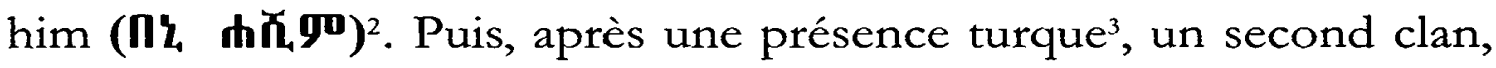
celui des Beni Humayya (ח々 $\mathbf{h} \mathbf{0 4 9}$ ), serait venu s'y établir. En désaccord sur l'islam, ayant même tué des descendants du Prophète comme Hussein et Hassan, ils se seraient enfuis d'Arabie pour s'établir à leur tour dans ces cités. Riches et orgueilleux, quasiment sans religion puisqu'ils mangeaient pendant les périodes de jeûnes, ne respectant au-

\footnotetext{
${ }^{2}$ Selon lui, Hajji Mansur aurait été ainsi un Beni Hashim.

${ }^{3}$ Est-ce une vague réminiscence de la présence turque aux côtés de l'Imam Ibrahim, ou sur le littoral et dans le nord de l'Éthiopie au $\mathrm{XVI}^{c}$ siècle ? Le même informateur nous précisera que ces Turcs étaient en fait les commerçants de ces cités.
} 
cune règle, ils ne craignaient pas Dieu. C'est un mariage qui provoqua la punition divine, un mariage qui aurait entraîné un an de fêtes extravagantes, six mois chez la promise et six mois chez le promis. Lors de ce mariage, les habitants d'Asbäri auraient osé paver la route d'Asbäri

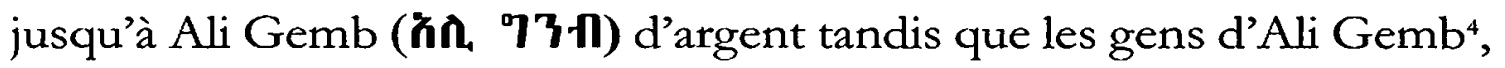
de leur côté, l'auraient tapissée d'injera jusqu'à Asbäri. En colère contre ces actions indignes, Dieu aurait alors frappé ces villes de sa malédiction : la terre aurait cessé de produire le coton, entraînant la destruction finale des cités. Ce récit légendaire de la malédiction divine suite à des dépenses somptuaires pour un mariage ${ }^{j}$ circule entre les gens du pays et est adapté aux différents sites (par exemple, à Nora, la route en pavés d'argent est réputée commencer à Nora et non à Asbäri). Ainsi, au moins pour cet informateur, comme pour d'autres interrogés - nous n'avons pas réussi à obtenir, pour l'instant du moins, en raison de leur méfiance et de leur situation de minoritaire, les versions, probablement différentes, conservées par les Argobba de la zone -, l'origine de ces villes est étrangère. Cela étant, cette séquence Beni Hashim-Beni Humayya n'est pas sans rappeler la succession des dynasties Mahzumites et Walasma, dont on sait qu'elles se rattachaient de façon légendaire à des clans opposés de La Mecque.

Étant donné la taille et la concentration de ces villes, il serait très surprenant qu'elles ne correspondent pas à l'une ou l'autre des cités musulmanes mentionnées dans cette région par les sources écrites musulmanes. On peut faire l'hypothèse que ces sites urbains, peut-être

\footnotetext{
${ }^{4}$ Ali Gemb est, d'après les gens du pays interrogés, un site en ruine assez similaire à ceux d'Asbäri, Mäsal et Nora, situé à 6 heures de marche au sud-ouest. Nous n'avons pas eu le temps de le visiter durant cette mission.

${ }^{5}$ Il faut noter qu'un récit à la structure exactement similaire a été recueilli dans le Tchertcher par Azaïs et Chambard pour expliquer la disparition de villes attribuées aux Harla.
} 
fondés à des époques différentes, ont été contemporains à un moment donné, vraisemblablement lors du rayonnement du royaume de l'Ifat au $X V^{e}$ et au début du $X^{e}$ siècle. Mais rien n'empêche aussi que ces cités, avant de rentrer dans l'orbite politique de l'Ifat, n'aient pas constitué auparavant un des pôles urbains (voire le coeur) du royaume musulman du Choa. C'est en tout cas l'idée que nous soumeurons à des recherches plus approfondies.

\section{Mosquées médiévales de l'Ifat}

I a prospection dont nous avons rendu compte ci-dessus a permis de repérer dans cette zone sept mosquées ou établissements religieux (la carte de repérage des sites montrent qu'elles sont alignées sur un axe $\mathrm{N}-\mathrm{S}$ ). I es trois principales, sur chacun des sites urbains, correspondent probablement à une mosquée du vendredi, alors que les autres, à l'intérieur des villes, étaient peut-être des mosquées de quartier, et celles situés sur des hauteurs isolées des lieux de retraites ou des oratoires'. L'ensemble dessine un dense réseau religieux. Seules les deux grandes mosquées d'Asbäri et de Nora sont encore utilisées aujourd'hui, une fois par an, lorsque les habitants des alentours viennent y célébrer une fête sous forme de pèlerinage.

Les mosquées montrent, au moins pour le mur d'enceinte, des similitudes frappantes. Le mur nord est le plus souvent le plus long et comporte une série de niches de part et d'autre du mibrab. Le mur sud semble presque toujours percé d'une seule porte (cependant les parties détruites empêchent d'être totalement affirmatif sur ce point) qui servait d'accès à la cour de la mosquée ou à l'intérieur du bâtiment,

\footnotetext{
' On se rappelle à ce propos la formule de al-'Umari, expliquant que dans les royaumes musulmans d'Éthiopie il y a " des mosquées cathédrales, des mosquées ordinaires et des oratoires, où l'on fait la hotba, la prière du vendredi et la prière en assemblée », mais pas de ₹āwìya. (Gaudcfroy-Demonbymes, $1927: 3$ )
} 
comme c'est le cas aussi de la mosquée de Gozé. Ce mur ne comporte jamais de fenêtres, contrairement aux murs ouest, et est toujours percé par une série d'ouvertures (le plus souvent deux ou trois), comme également dans la mosquée de Fäqi Dabbis. Seules les grandes mosquées d'Asbäri et de Nora montrent encore des traces d'aménagement intérieur : séric dc pilicrs à $\Lambda$ sbäri qui délimitait l'espace clos dédié aux prières, un pilier seulement subsistant à Nora, qui indique peut-être un espace similaire ${ }^{7}$.

Par ailleurs, les mosquées de Nora et d'Asbäri montrent clairement les traces de minarets - ce qui contredit l'affirmation de Chernet Tilahun qui parle d'une chambre secrète pour l'ouverture du minaret à Nora et d'un second mibrab pour le minaret d'Asbäri (Chernet Tilahun, 1990 : 308). Il s'agit de constructions adossées au mur d'enceinte (à Asbäri sur le mur ouest, à Nora sur le mur de la qibla), avec une ouverture sur le bas et un escalier qui permettait d'accéder au toit de la mosquée pour l'appel à la prière. Ce minaret n'était probablement pas très élevé par rapport à la surface du toit.

\section{Cimetières musulmans}

Les nombreux cimetières de la région sont presque toujours (à l'exception de celui d'Hajji Mänsur) liés à des sites urbains et situés généralement en contrebas et au nord des villes. Ils atteignent parfois, comme à Asbäri, des surfaces considérables. On a vu plus haut que nous avons pu établir une première typologie sommaire de ces tombes :

\footnotetext{
${ }^{7}$ Nos recherches antérieures dans la mosquée en ruines de Fäqi Dabbis ont montré que ce bâtiment était entièrement couvert par un toit plat, soutenu par une série de piliers, comme on peut le voir encore dans la mosquée de Gozé. La taille de la mosquée d'Asbäri rend difficile une couverture complète et présentait probablement un plan différent, avec une cour à ciel ouvert devant le bâtiment couvert. L'état des autres mosquées ne permet pas d'affiner pour l'instant ces comparaisons.
} 


\section{RECONNAISSANCE DE TROIS VIIIES MUSULMANES}

le type ancien qui semble le plus fréquent dans cette région, auquel nous ne pouvons pas encore assigner de dates précises, est celui d'une structure quadrangulaire formée de quatre blocs de pierre taillés, de hauteur égale, faisant une sorte de coffrage, orientée E-W, sans stèle dressée et sans inscription funéraire. Ce type montre plusieurs variantes en fonction de la qualité de la pierre et du soin apportée à la taille : blocs très bien taillés du cimetière ancien de Mäsal, blocs plus grossièrement découpés ou encore, variante la plus répandue, série de pierres remplaçant les blocs taillés des côtés. En l'absence de datation, il est délicat de proposer une interprétation solide de ces variations; mais si ce type de tombes caractérisait les cimetières médiévaux, il serait tentant d'y lire une hiérarchie sociale, au sommet de laquelle on trouverait le type exceptionnel de la tombe monolithe d'Ali, puis les tombes avec blocs taillés. Enfin, il faut garder à l'esprit que ces tombes ne peuvent être toutes attribuées a priori à des musulmans ; une tombe contemporaine érigée pour un chrétien, avec une croix plantée en son sommet, parmi les tombes musulmanes du cimetière d'Hajji Mänsur, est là pour nous rappeler ce principe de précaution.

Il sera dans l'avenir très utile de comparer ces tombes avec celles connues dans d'autres régions musulmanes pour les périodes anciennes. Le type que nous venons de décrire ne semble pas en tout cas avoir été décrit jusqu'à présent et se distingue nettement d'un type plus généralement connu dans l'Éthiopie musulmane avec deux stèles dressées, à la tête et aux pieds du mort (Gori, 2005 : 875), comme les tombes (actuelles) de Harar décrites par Abdulla Abdurhaman (1953: 17) :

"The burial is completed by erecting the gravestone on the either side of the grave. The gravestones are usually a pair of flat white rocks, often carved into artistic shapes, one of them slightly 
bigger than the other. They are erected on the top of the grave facing one another on the north and south ends, the bigger one being located on the northern end, i.e. directly above the head of the buried body. A short epitaph "God bless his (her) soul" coupled with the date of birth and death is written always on the bigger block. The two main grave-stones are then joined by linings of small stones on their adjacent sides so as to show the rectangular outline of the grave. A distinctive cylindrical piece of stone is inserted in the middle of the rectangle on women's graves".

Comme on le voit dans cet exemple, ces tombes sont normalement orientées avec la tête du mort en direction de La Mecque, contrairement aux tombes prospectées dans cette région de l'Ifat qui sont orientées Est-Ouest. On remarquera en ce sens l'analogie frappante entre ce dernier type de tombe et l'architecture et l'orientation des mosquées de cette région. Il est possible aussi que ces différences typologiques entre les tombes, et en particulier les orientations divergentes, soient liées à des différences de rites funéraires pratiqués selon les deux écoles juridiques (hanéfite et shaféite) dont on sait qu'elles ont été concurrentes dans l'Éthiopie musulmane.

Étant donné le manque d'études détaillées à ce propos, l'absence regrettable de descriptions précises des tombes dans les prospections anciennes - les stèles funéraires portant des inscriptions sont souvent analysées sans que l'on sache comment se présentait le monument funéraire -, il nous faut nous contenter pour l'instant de remarquer que nous n'avons pas trouvé le type de tombes avec stèles décrit par Azaïs et Chambard (1931 : 140-142, pl. XXXI et XXXII) dans la partie occidentale des monts Tchertcher (comme les tombes de la région de Heissa) Nous n'avons pas pour l'instant non plus repéré de stèles épigraphiées comme celle de la région du Harar et du Tchertcher décou- 
RECONNAISSANCE DE TROIS VILLES MUSULMANES

vertes en particulier par les mêmes Azaïs et Chambard, ou celles décrites et étudiées par Madeleine Schneider dans la région de Quiha ou dans le Choa (Schneider 1967, 1970). Mais l'inventaire n'en est qu'à son début et cette étude de la typologie des tombes et de leur comparaison avec d'autres régions musulmanes d'Éthiopie devra faire l'objet d'un travail spécifique.

Aujourd'hui, les cimetières de Mäsal et Hajji Mänsur, dont les tombes anciennes sont attribuées à des Arabes par les habitants, sont célébrés chaque année au mois de décembre à Mäsal, en juin et en octobre à Hajji Mänsur. À Mäsal, à l'ombre d'un acacia situé à la frontière entre le cimetière ancien et le cimetière plus récent, les hommes font une prière et partagent un repas fait de viande de bœuf, de pains traditionnels et de qollo ( $\mathbf{(}^{\boldsymbol{n}^{\circ}}$ ) (blés ou orges grillés), tandis que les femmes participent à bonne distance en préparant la cuisine et en servant le café. À Hajji Mänsur, un rassemblement similaire se fait près de la tombe d'Ali au mois de juin ; en octobre, les habitants s'y réunissent à nouveau pour présenter les prémices des moissons, en particulier les

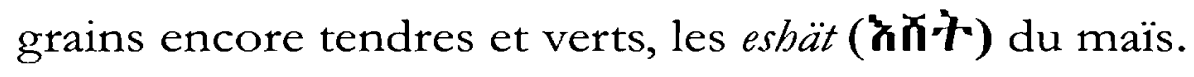

\section{RÉFÉRENCES}

Abdulla Abdurahman, 2002, "Harari Funeral Customs", Ethnological Society Bulletin, 1, 1953, reprint Alula Pankhurst (ed), p. 16-18.

Al-OMARI, 1927, Masalik el Absar fi Mamalik el Amsar, I, L'Afrique moins l'Égypte, traduit et annoté par Gaudefroy-Demombynes, Paris, Geuthner.

AzAÏs R.P. \& CHAMBARD R., 1931, Cinq années de recherches archéologiques en Éthiopie. Province du Harar et Éthiopie méridionale, Paris, Geuthner, texte (331 p.) et atlas (110 pl.) 
Cerulli Enrico, 1931, « Documenti arabi per la storia dell'Etiopia », Memorie della Reale Accademia Nazionale dei Lincei, serie VI, vol. IV, p. 39-101.

Cerulli Enrico, 1941, "Il sultanato delle Scioa nel secolo XIII secondo un nuovo documento storico", Rassegna di Studi Etiopici, I, p. 5-42

Chernet Tilahun, 1990, "Traces of Islamic Material Culture in North-Eastern Shoa", Proceedings of the First National Conference of Ethiopian Studies, Addis Abeba, p. 303-320.

CraWford O.G.S., 1958, Ethiopian Itineraries ca. 1400-1524, Cambridge.

GAUDEFROY-DEMOMBYNES. Voir AL-OMARI.

GoRI Alessandro, 2005, "Grave Culture in the Muslim Regions", Encyclopaedia Aethiopica, t. II, p. 875-76.

Hirsch Bertrand \& FAuvelle-Aymar F.-X., 2002, « L'Éthiopie médiévale. État des lieux et nouveaux éclairages », Cahiers d'Études africaines, 166, XLII-2, p. 315-335.

Hirsch Bertrand \& FaUvelle-Aymar F.-X., 2004, « Cités oubliées. Réflexions sur l'histoire urbaine de l'Éthiopie médiévale $\left(\mathrm{XI}^{\mathrm{e}}\right.$ XVI siècles) », Journal des Africanistes, 74 (1-2), p. 299-314.

KebedDE Geleta, 2000, "A Survey of Argobba Sites in Northern Shoa", Annales d'Éthiopie, vol. XVI, p. 185-194.

Poissonnier, Bertrand, Bernard Régis \& Farago Bernard, mai 2000, Report on the Gadilloméda-Gozé Mission (CFEE-ACI), Addis Abeba, 4 p. +16 figures.

SCHNEIDER Madeleine, 1967, « Stèles funéraires arabes de Quiha », Annales d'Éthiopie, VII, p. 107-118.

SCHNFIDER Madeleine, 1970, «Stèles funéraires de la province du Choa ", Annales d'Éthiopie, VIII, p. 73-78.

Traversi, 1893, « Le antichità di Uorcamba nello Scioa », Boletino della Società Geografica Italiana, serie III, vol. VI, p. 681684. 


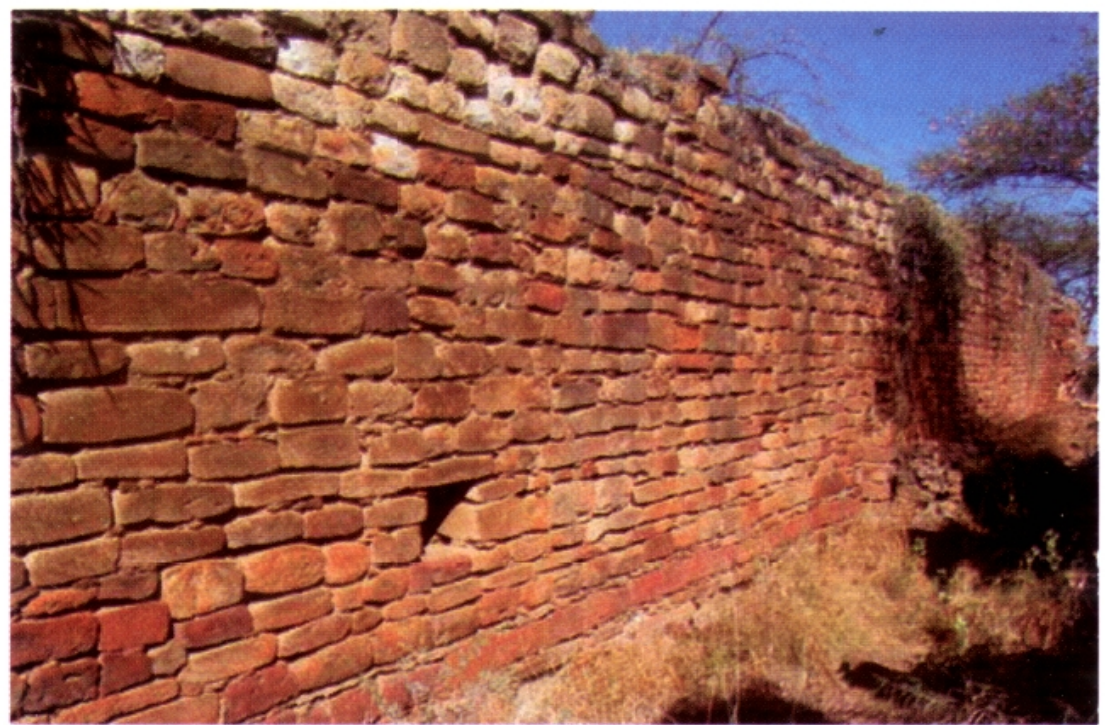

Photo 1 - Mosquée d'Asbäri : mur d'enceinte

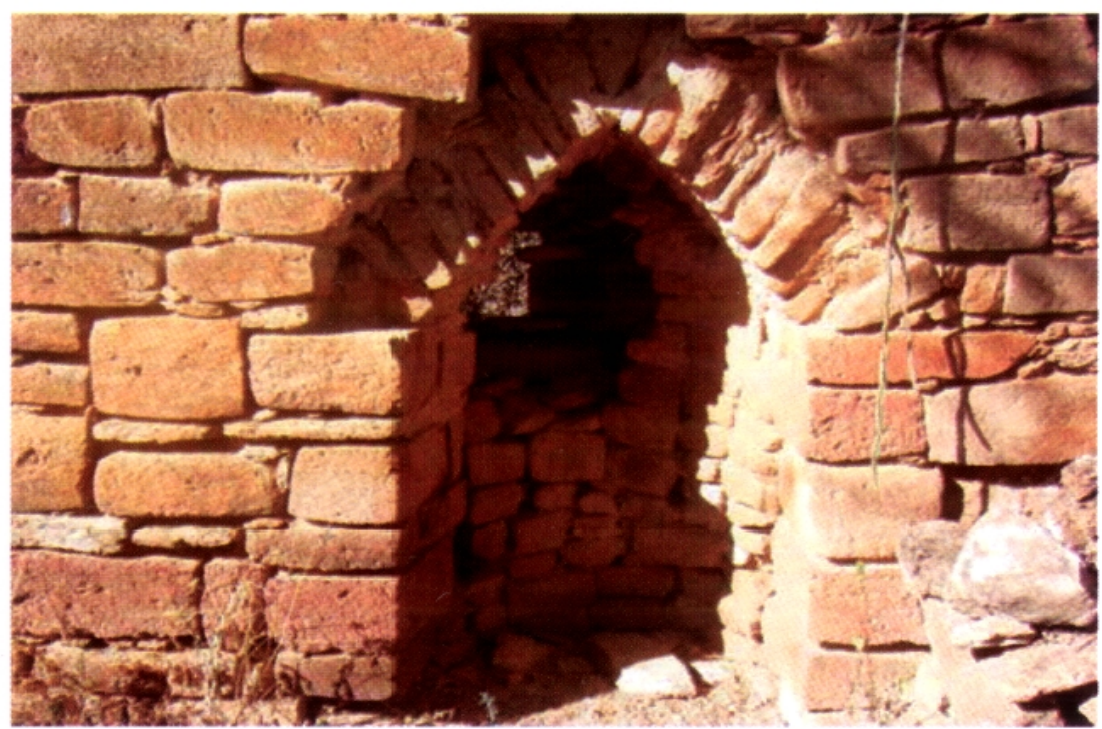

Photo 2 - Mosquée d'Asbäri : le mibrab

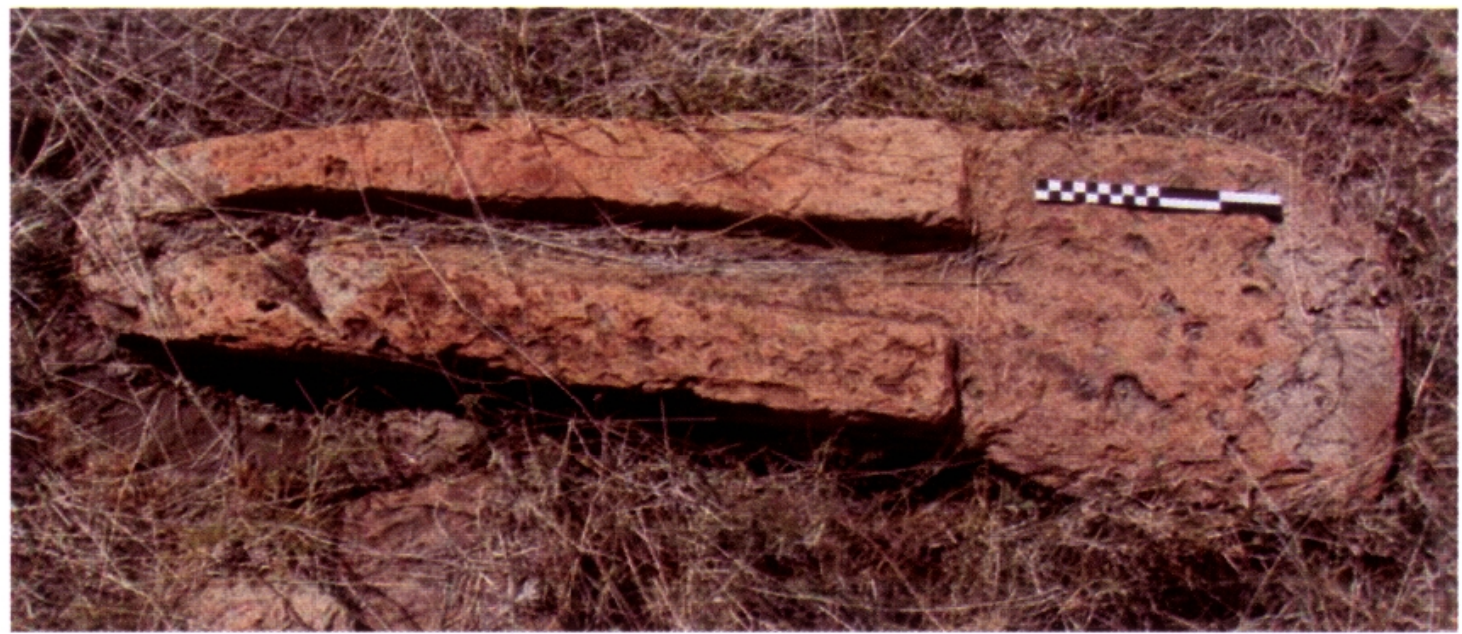

Photo 3-Asbäri : segment de "gouttière " à proximité de la mosquée 
166

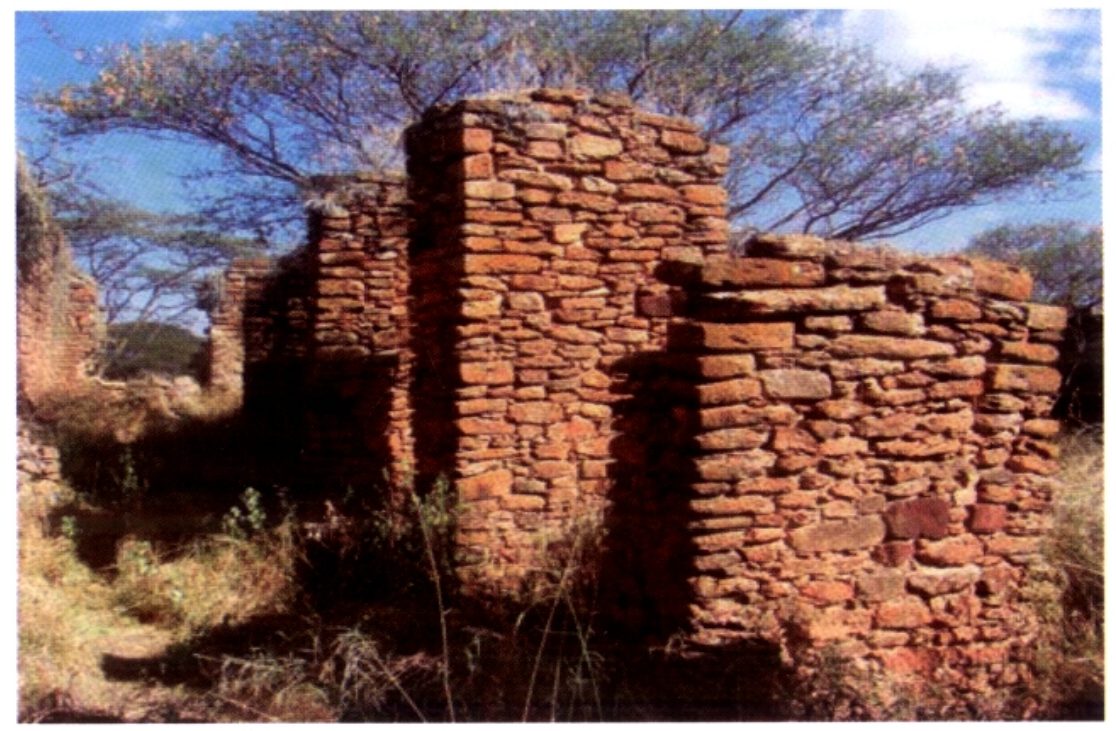

Photo 4-Mosquée d'Asbäri : première rangée de piliers

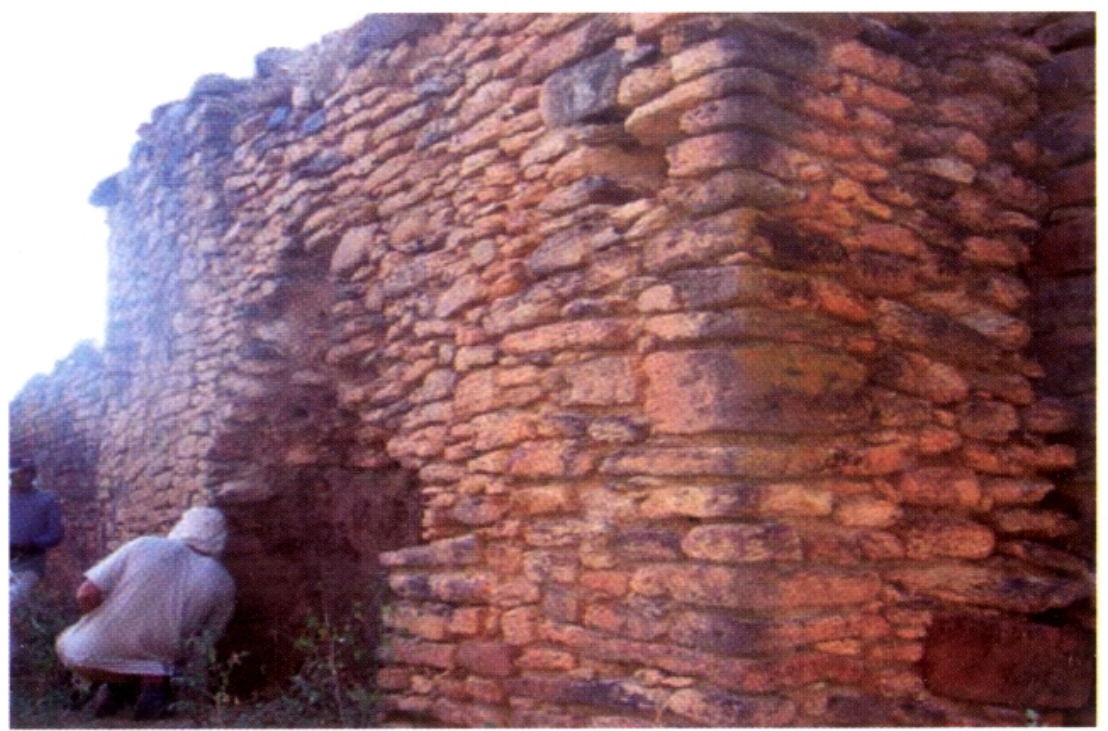

Photo 5-Mosquée d'Asbäri : minaret? 


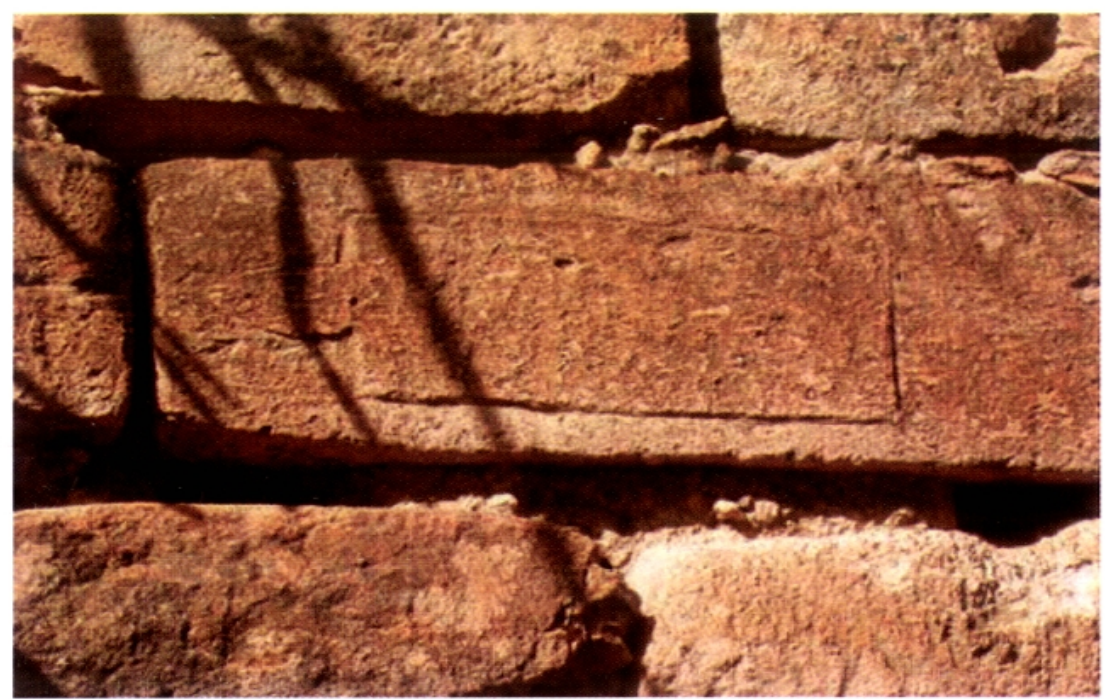

Photo 6-Mosquée d'Asbäri : tablette de prière en relief sur le mur d'enceinte.

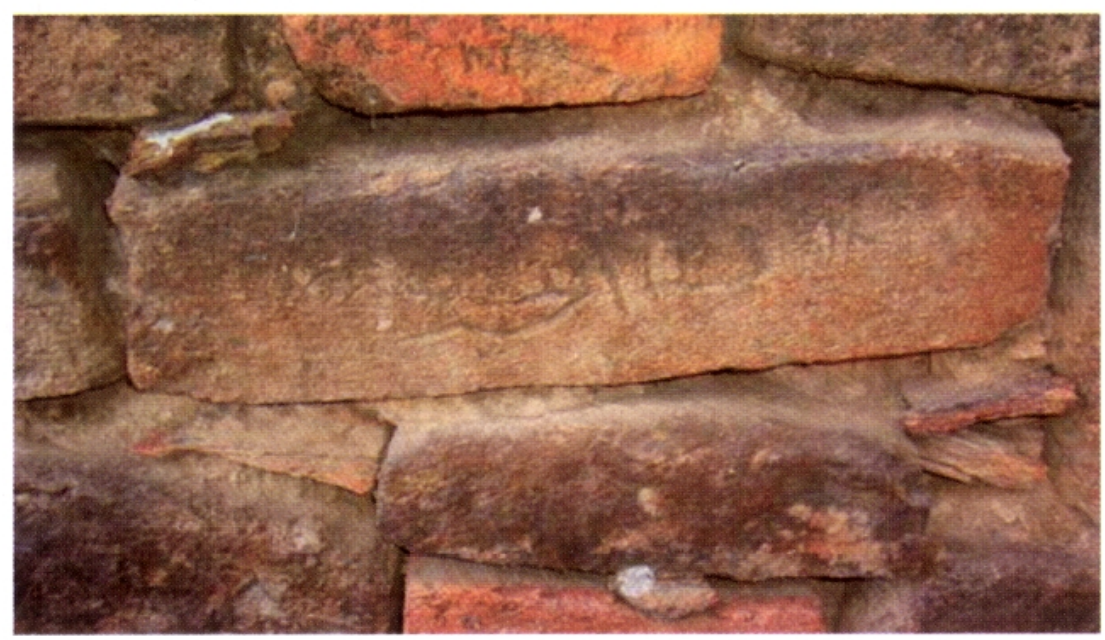

Photo 7-Mosquée d'Asbäri : Inscription gravée sur le mur d'enceinte

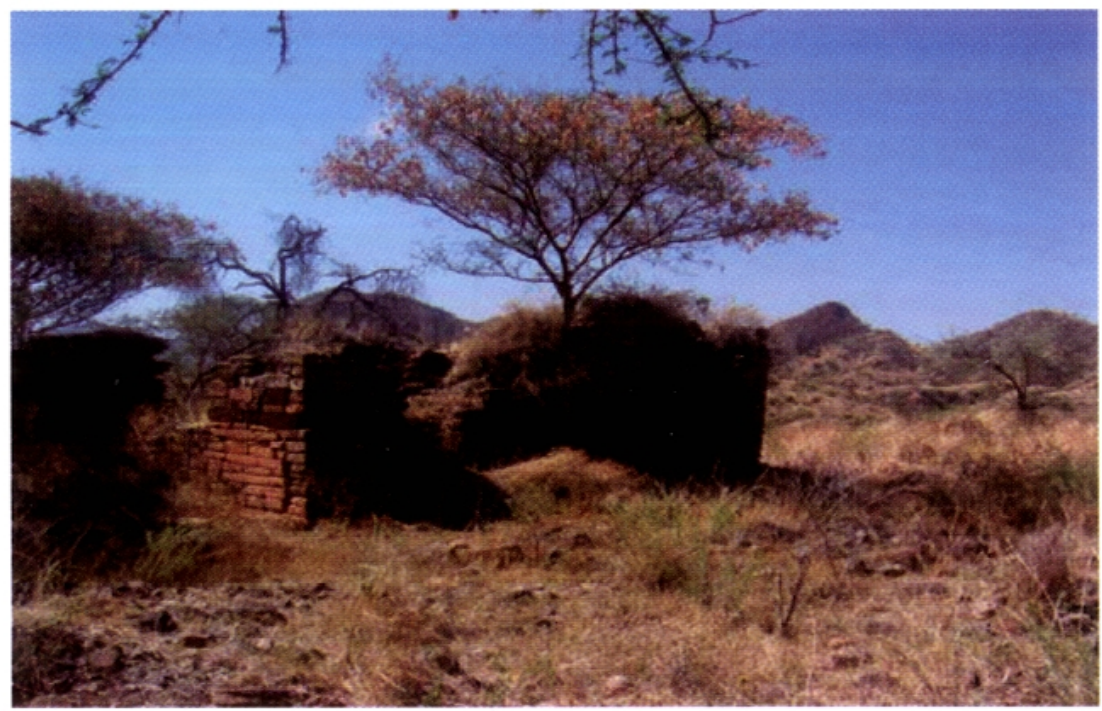

Photo 8-Asbäri : première petite mosquée 


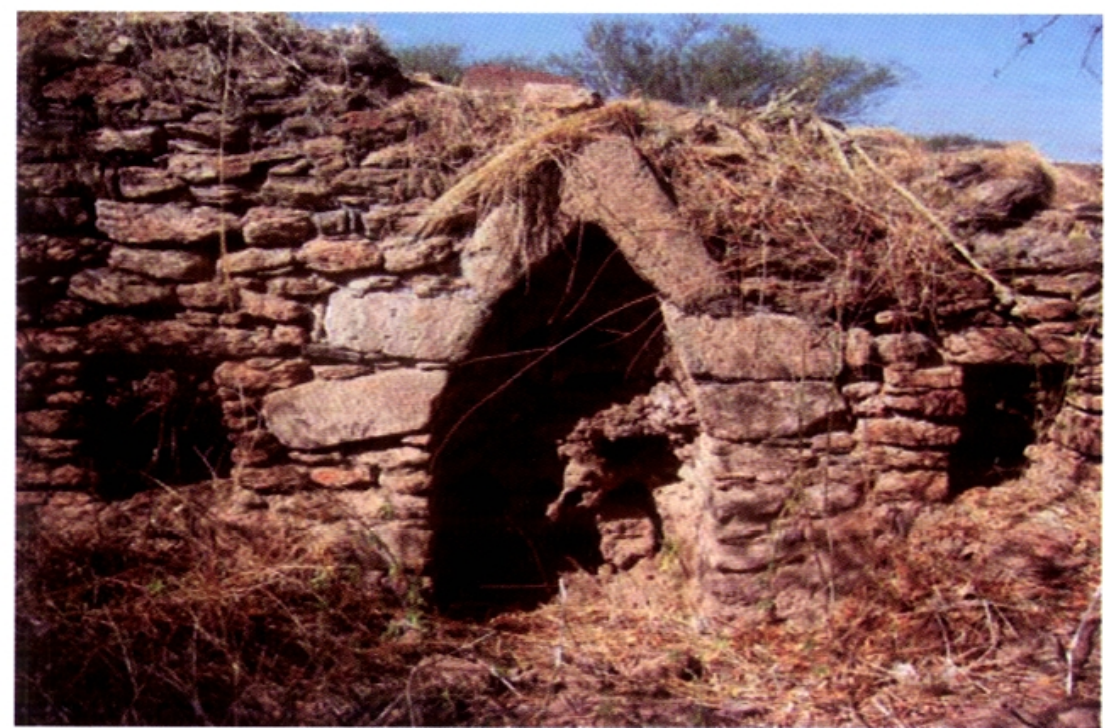

Photo 9-Asbäri : mibrab et niches de la seconde petite mosquée

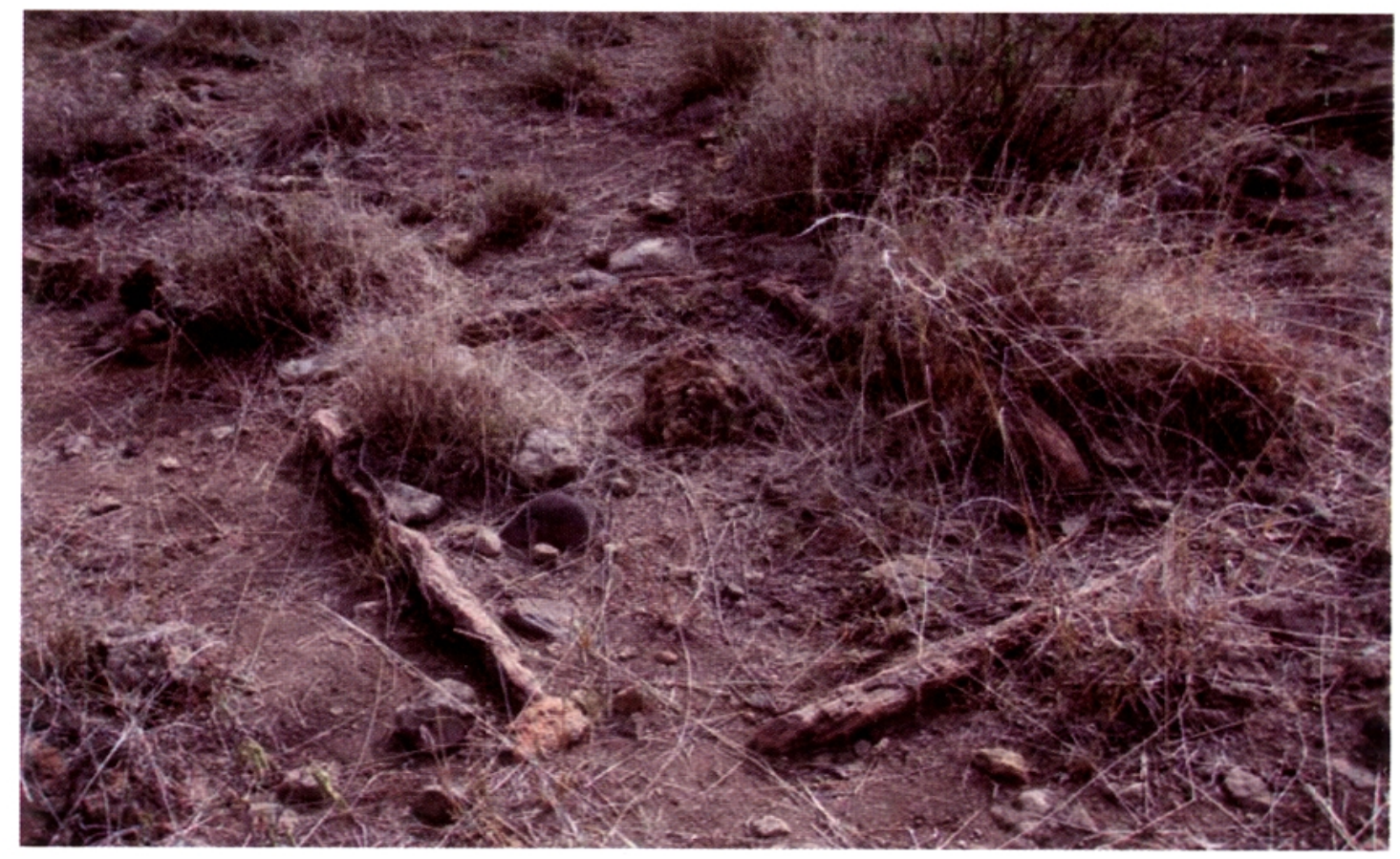

Photo 10-Asbäri : cimetière 


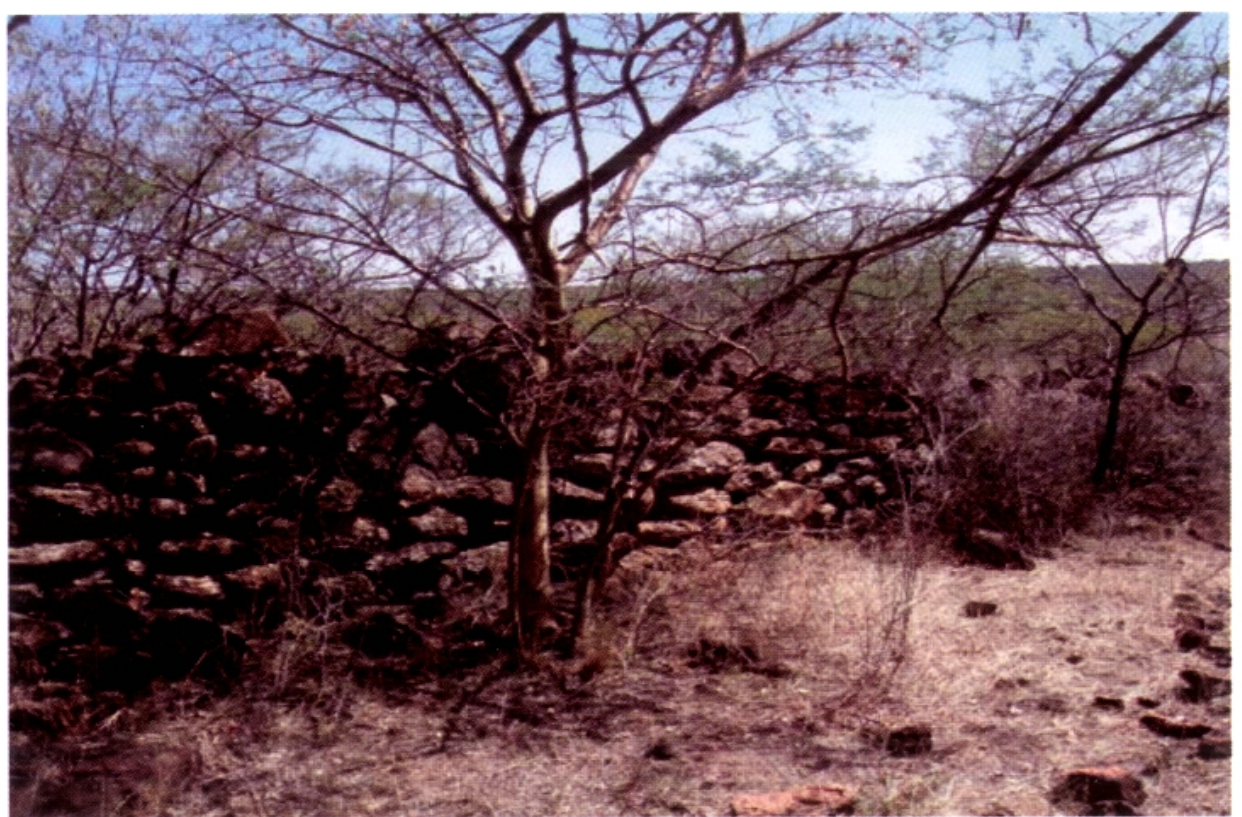

Pboto 11 - Asbäri : mur à l'est du site

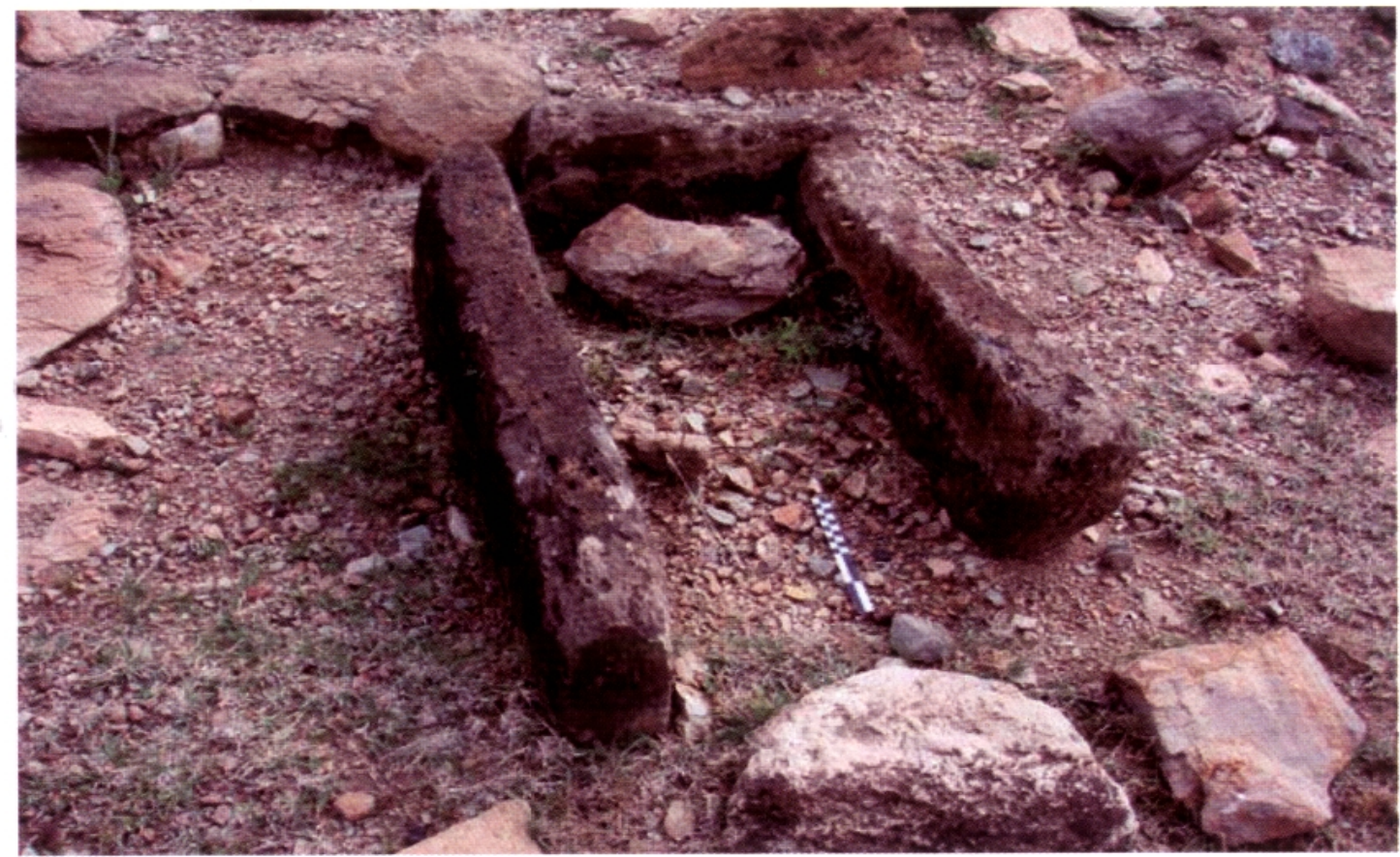

Photo 12 - Cimetière de Mäsal : tombe de type 1 


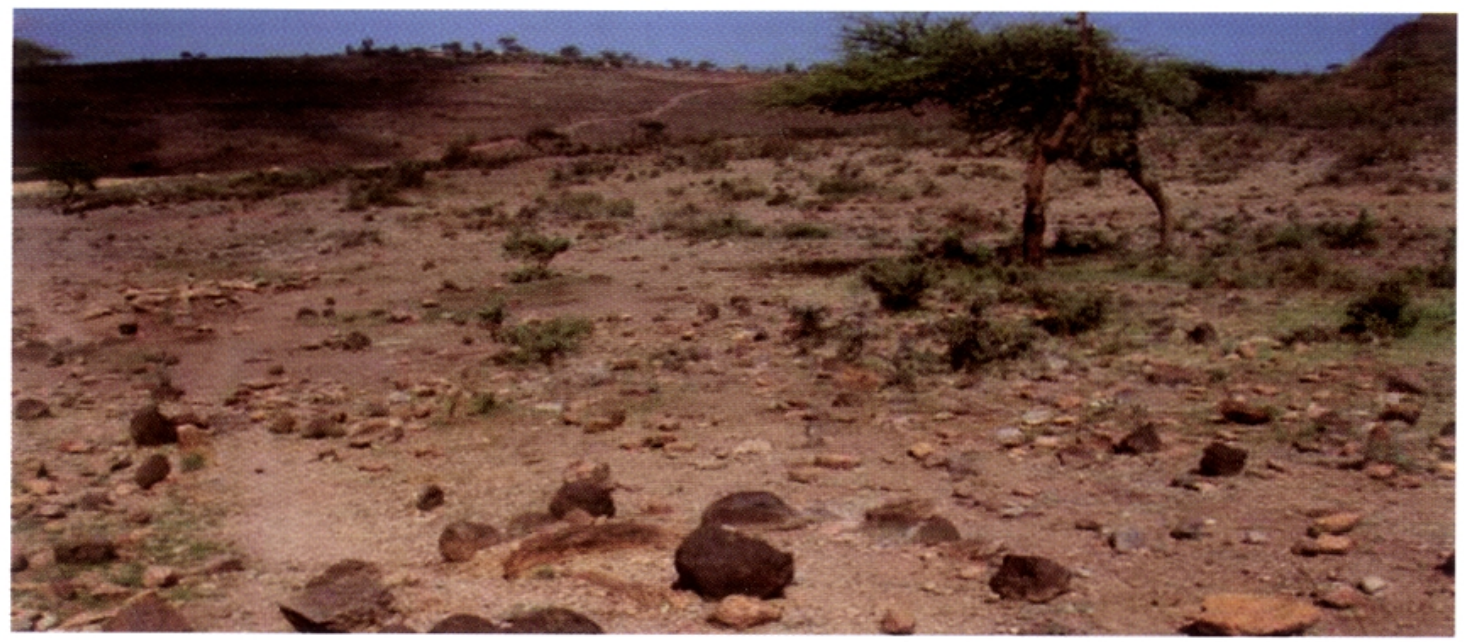

Photo 13 -Cimetière de Mäsal: tombe de type 2

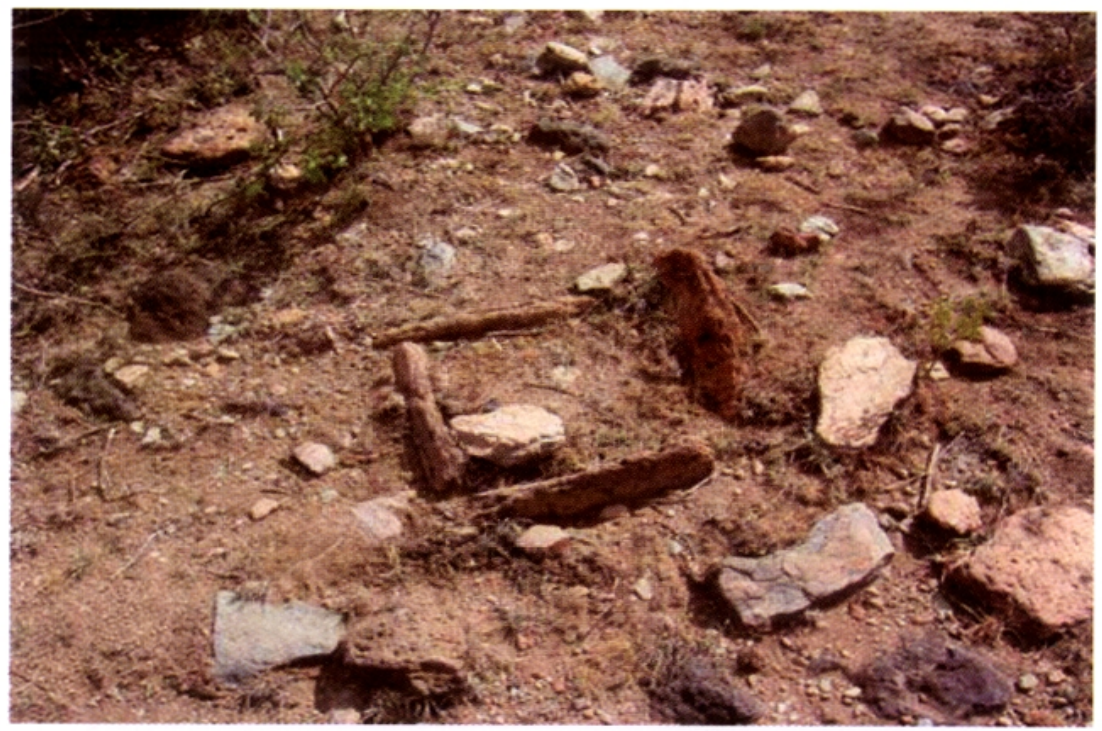

Photo 14 - Cimetière de Mäsal : tombe de type 3

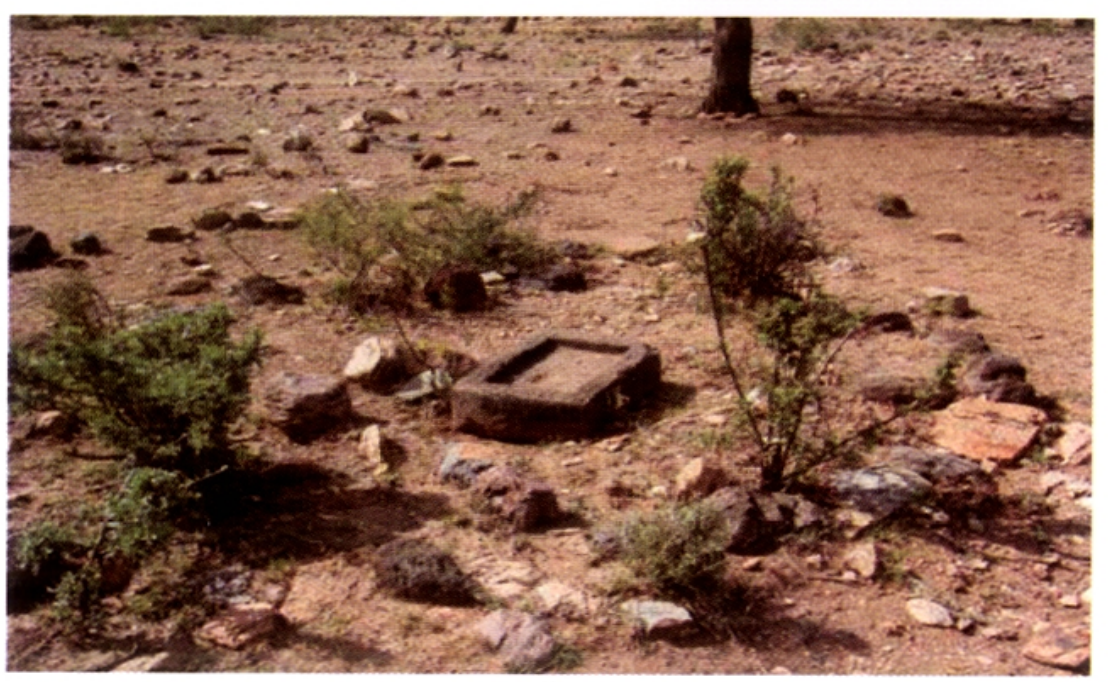

Photo 15 - Cimetière de Mäsal: tombe de type 4 


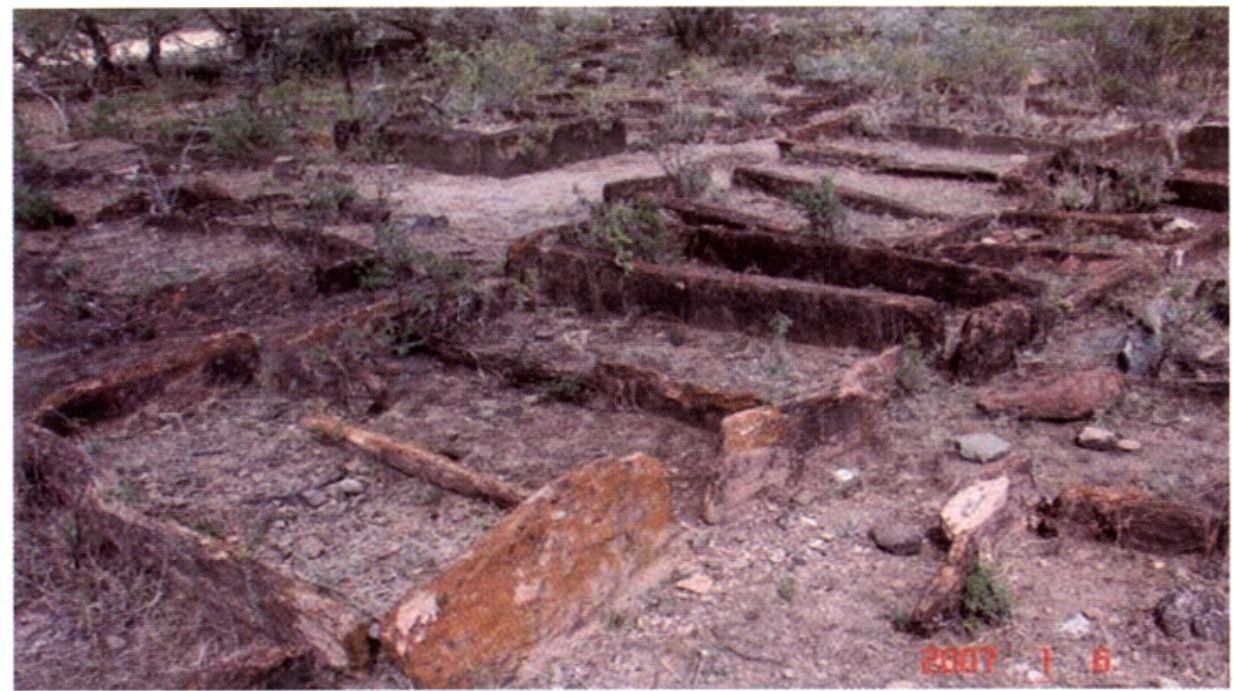

Photo 16 - Mäsal : cimetière supérieur (tombes anciennes)

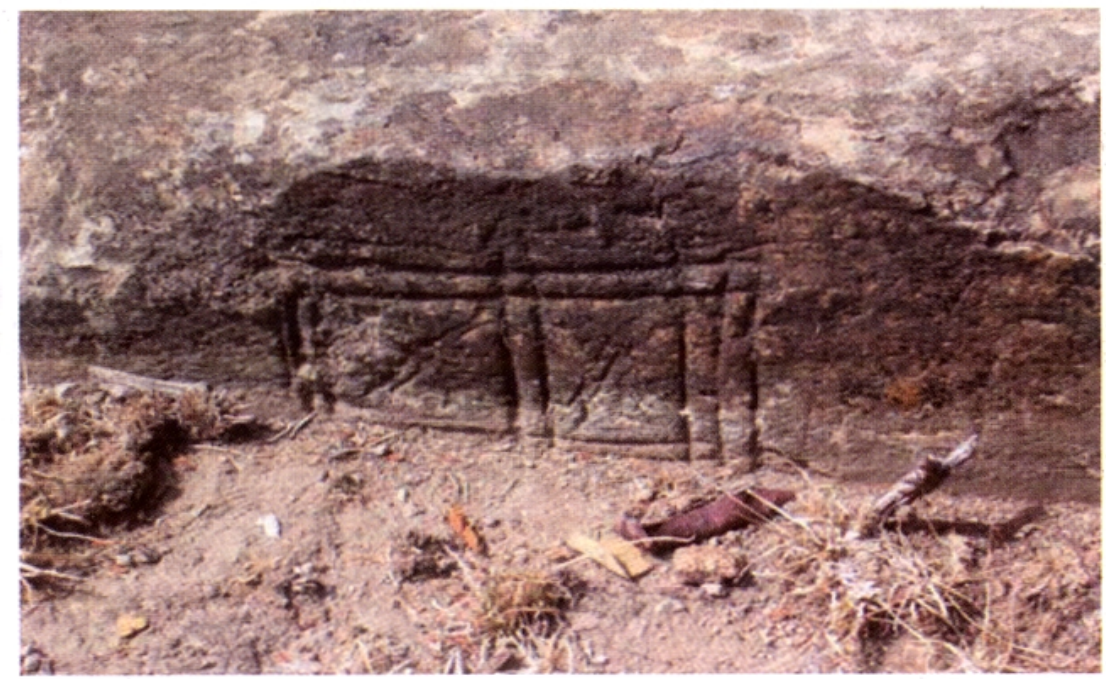

Photo 17 - Mäsal : cimetière supérieur (inscription sur une tombe ancienne)

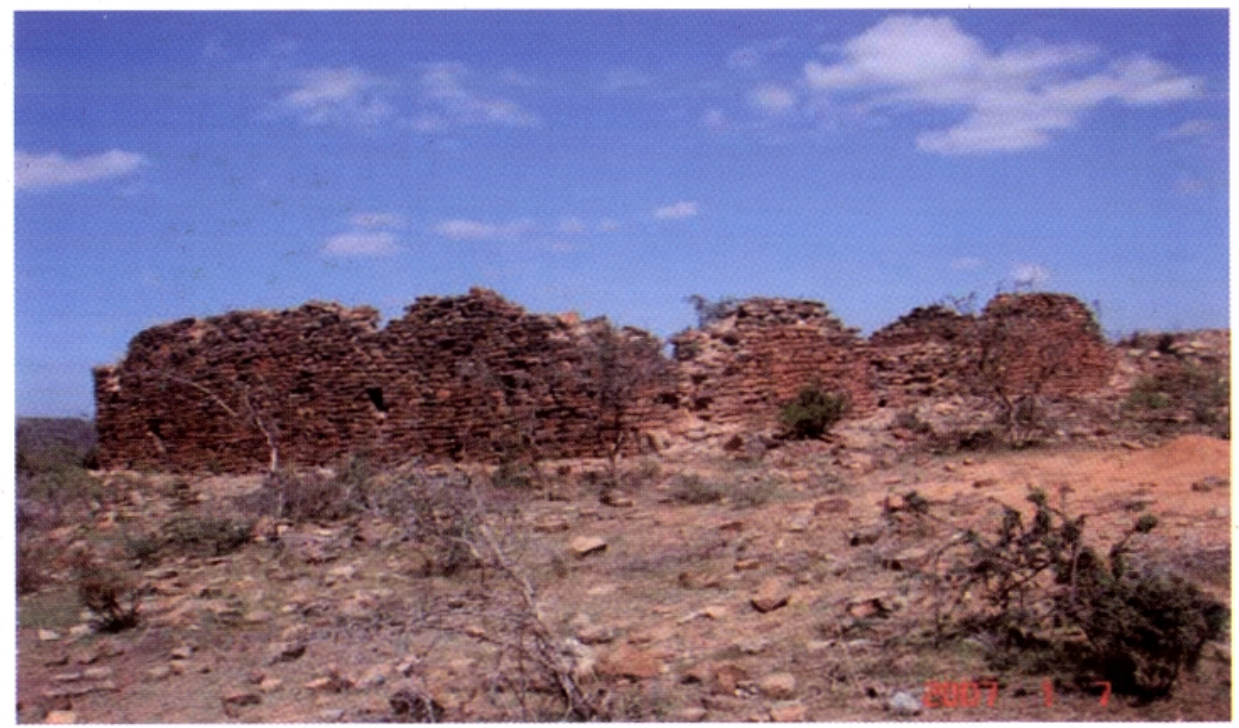

Photo 18 - Mäsal : mosquée Mäsgid Lé-alé 


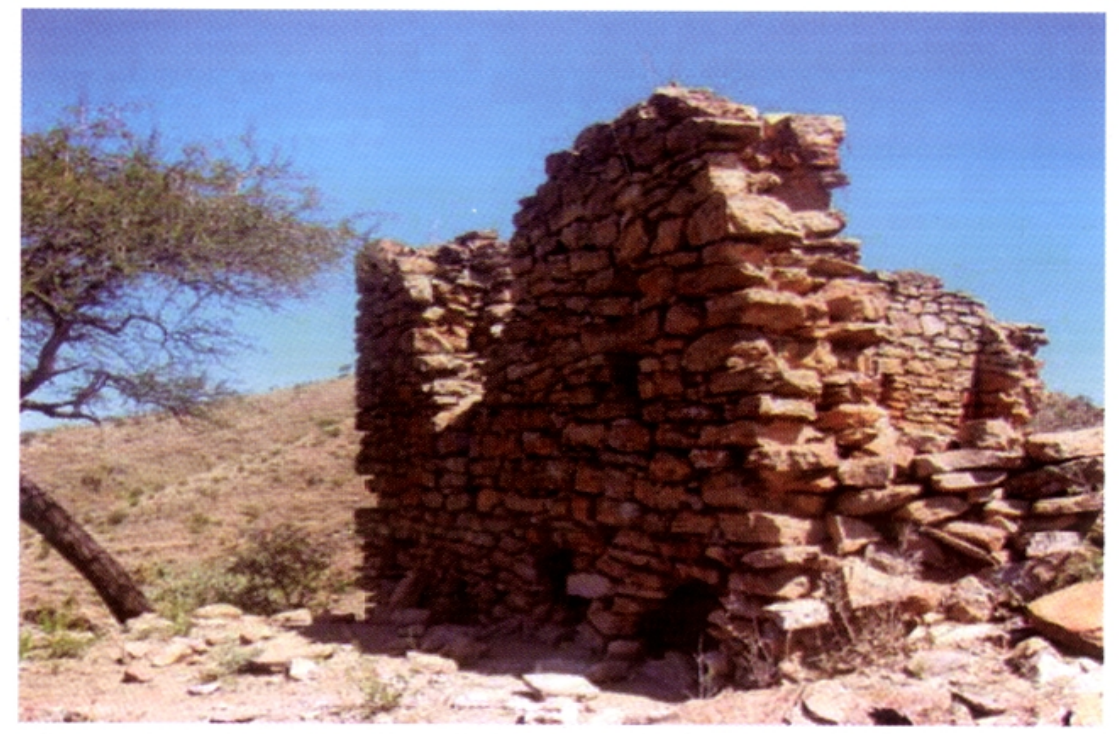

Pboto 19-Mosquée de Rassa Guba

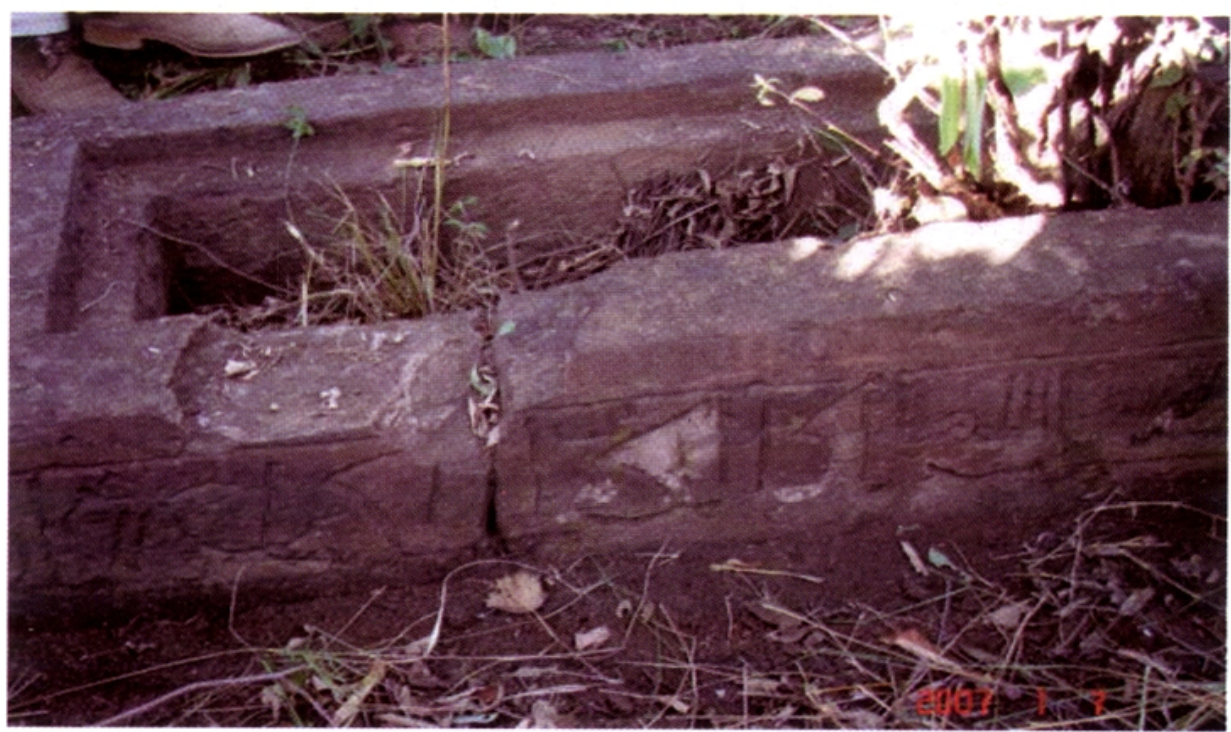

Photo 20-Cimetière de Haji Mänsur : tombe d'Ali

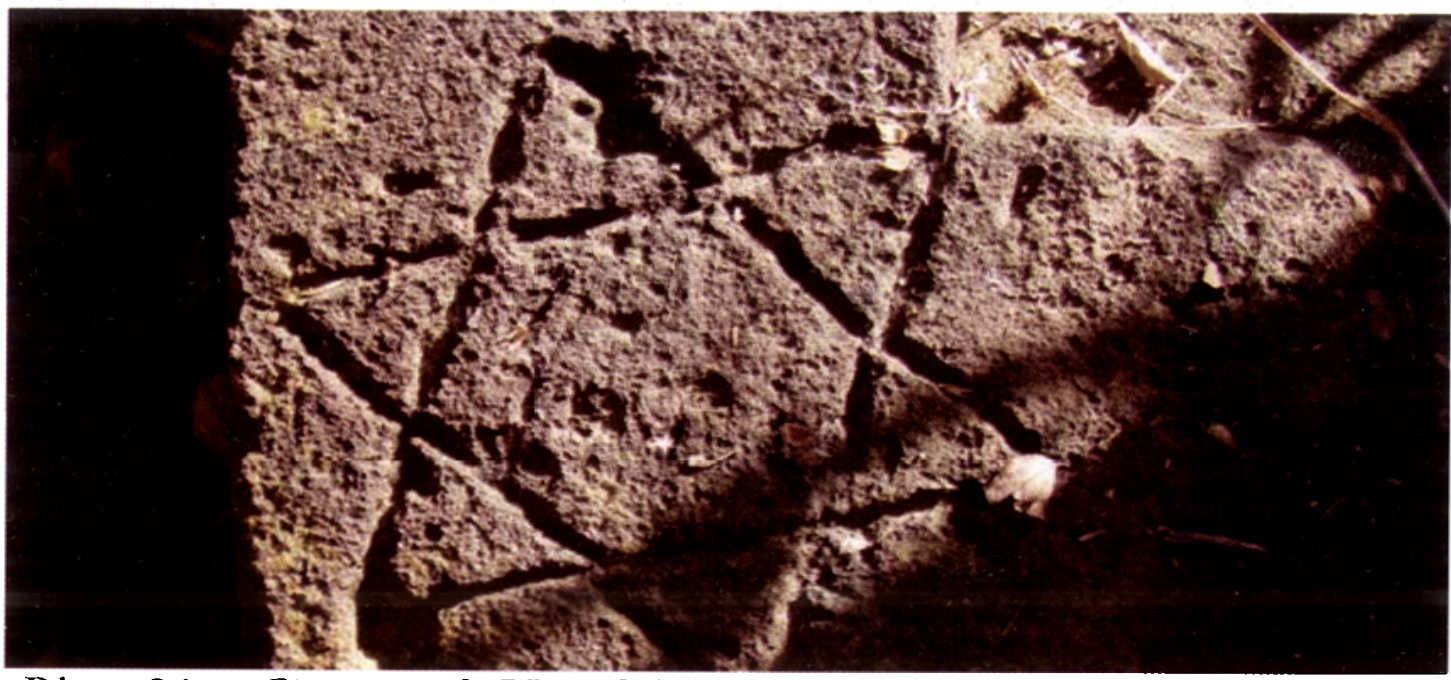

Photo 21 - Cimetière de Haiji Mänsur : tombe d'Ali (détail : étoile gravée) 


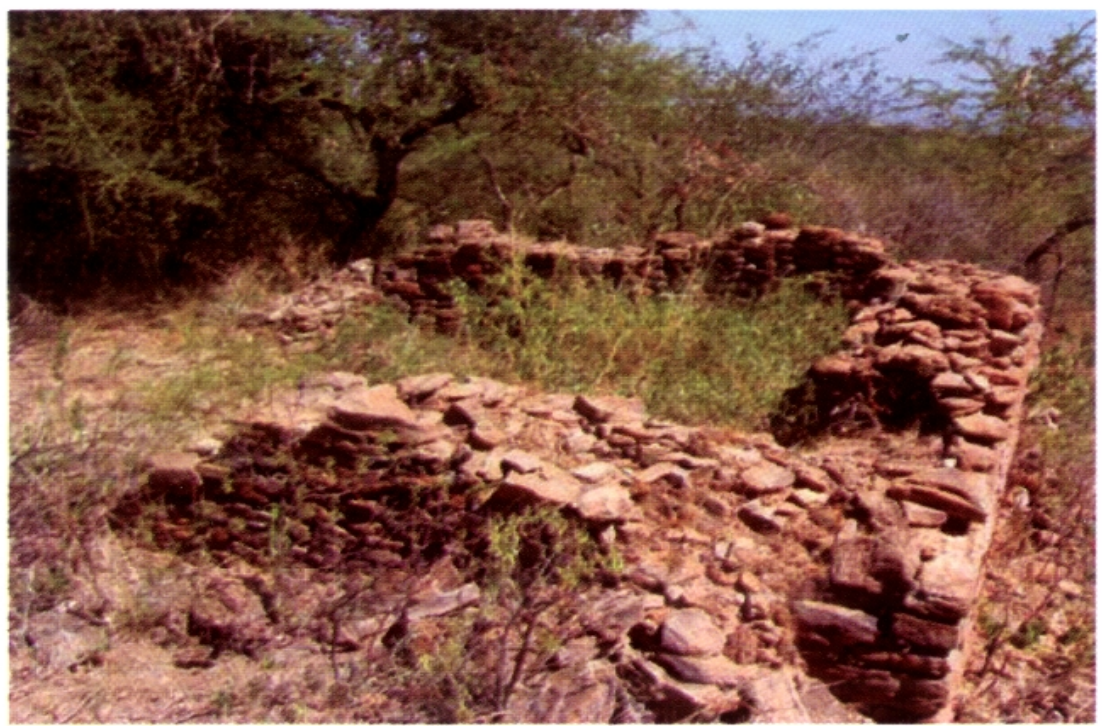

Photo 22 - Nora : ruine d'babitation

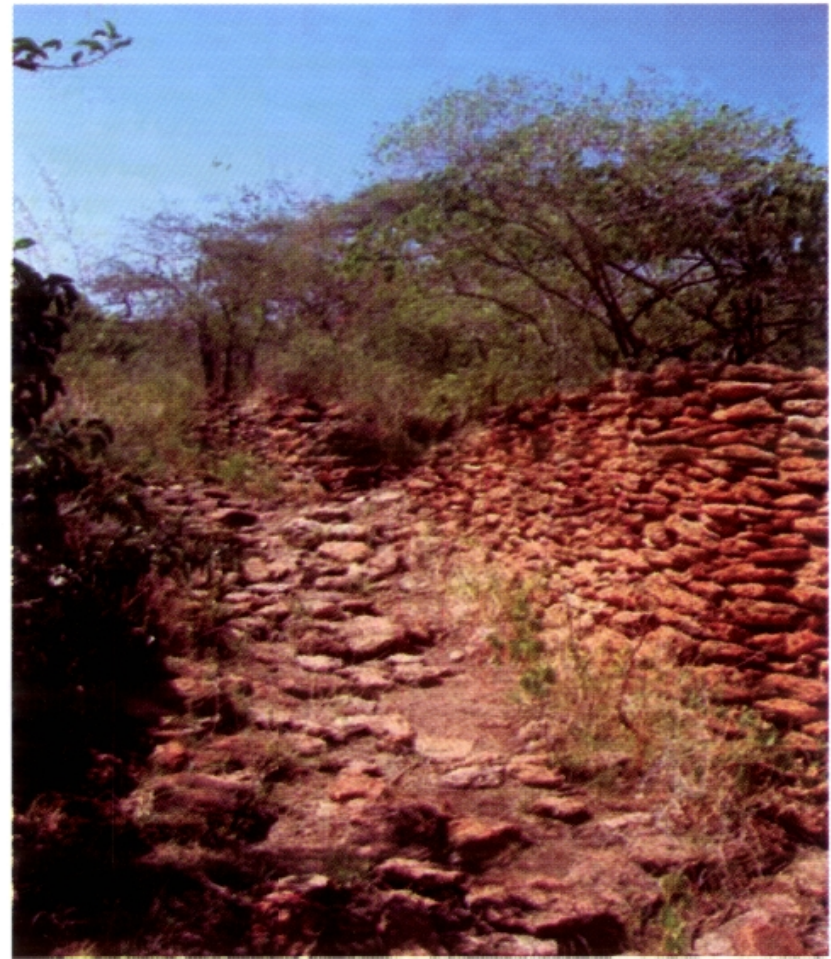

Photo 23 - Nora : rue partant de la muraille 


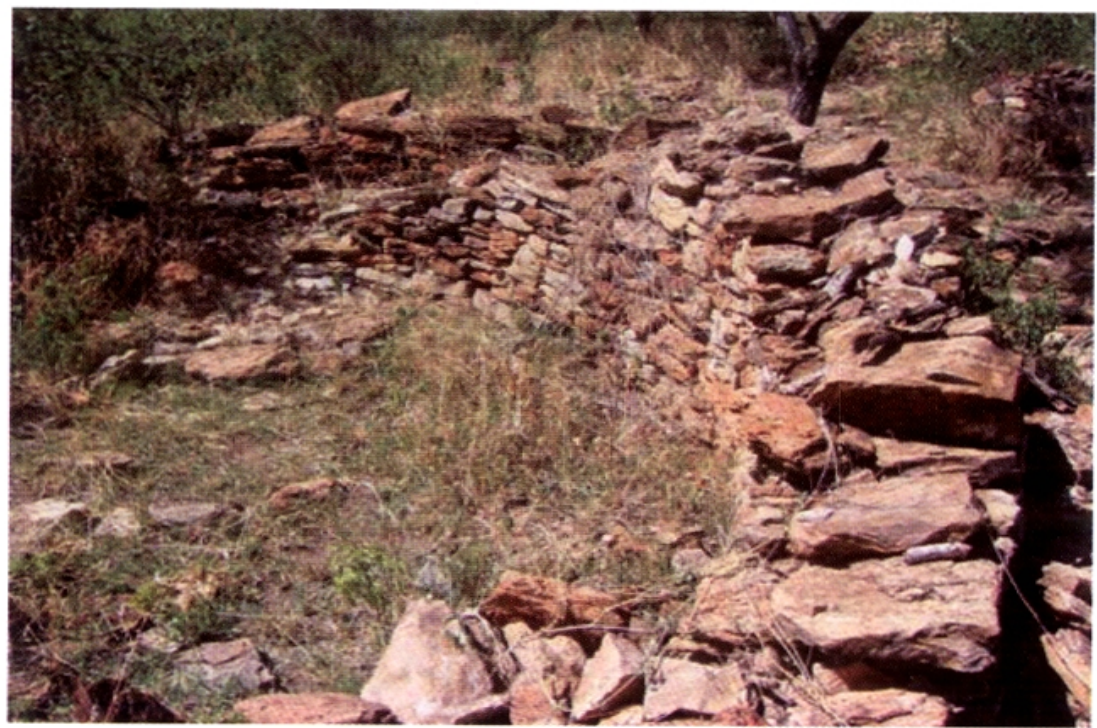

Photo 24 - Nora : ruine circulaire

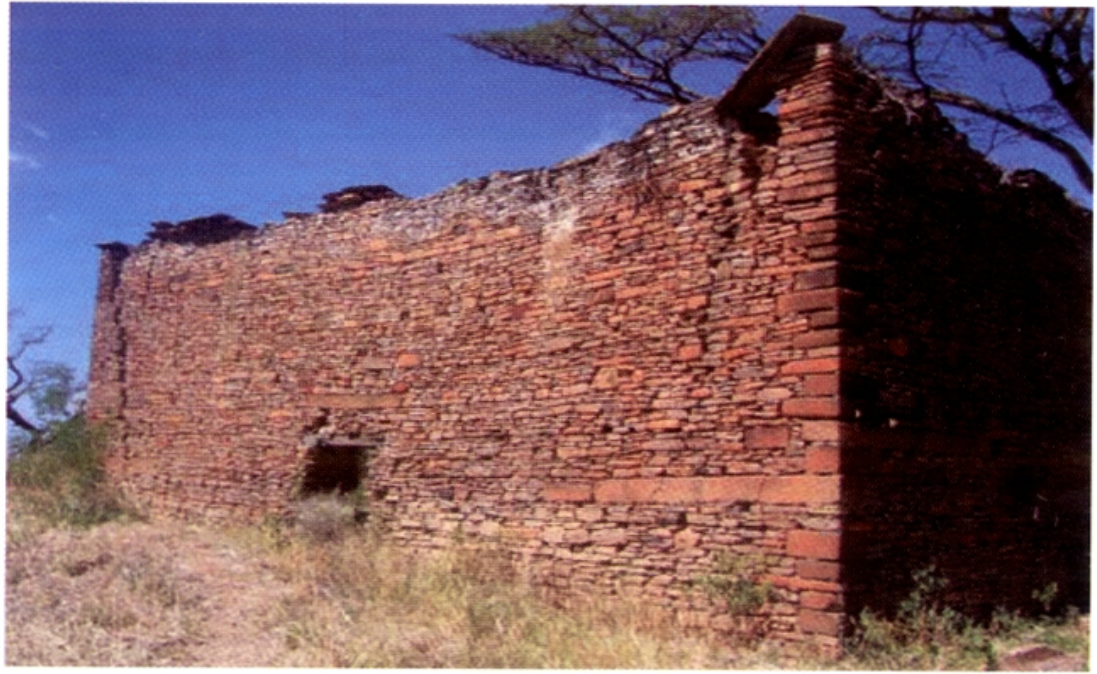

Photo 25 - Nora : mosquée (vue du mur sud)

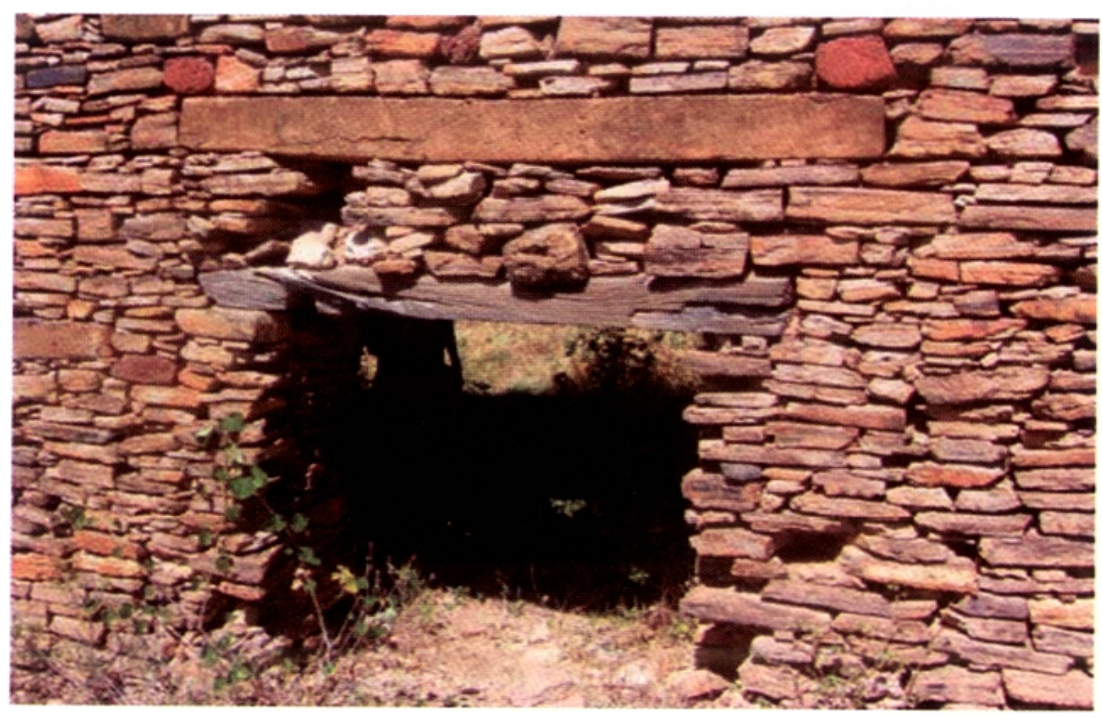

Plsoto 26 - Nora: mosquée (vue intérieure de la porte d'entrée) 


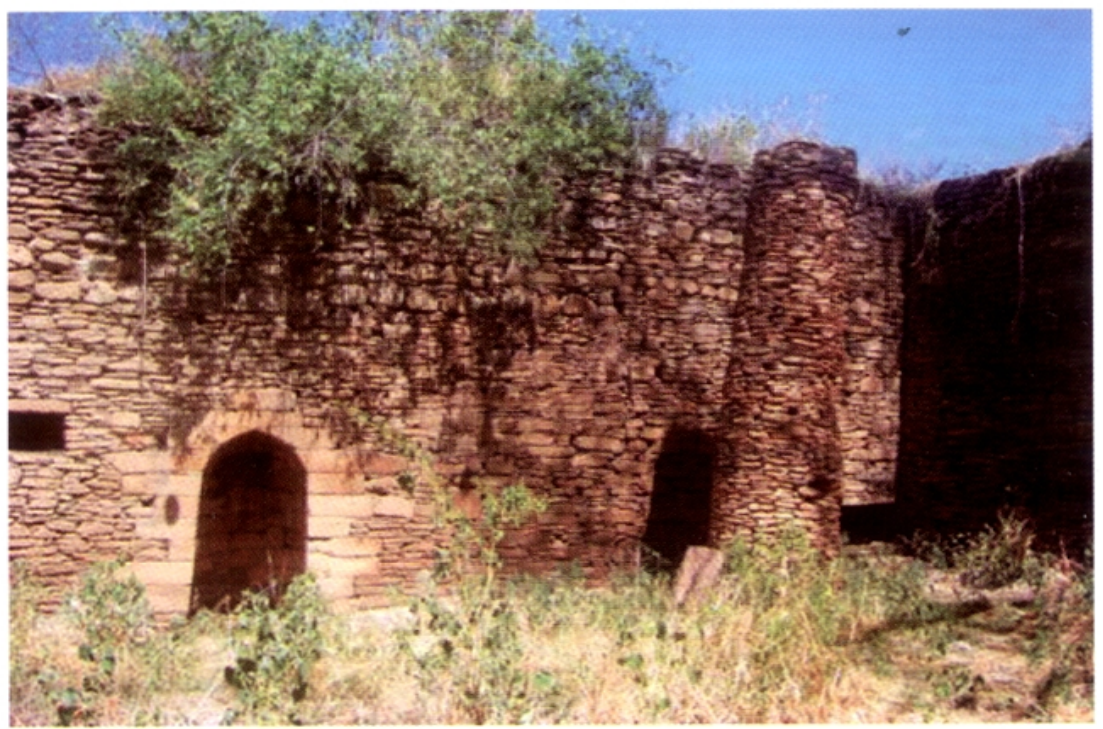

Photo 27 - Nora : mosquée (niche, qibla, colonne, entrée du minaret)

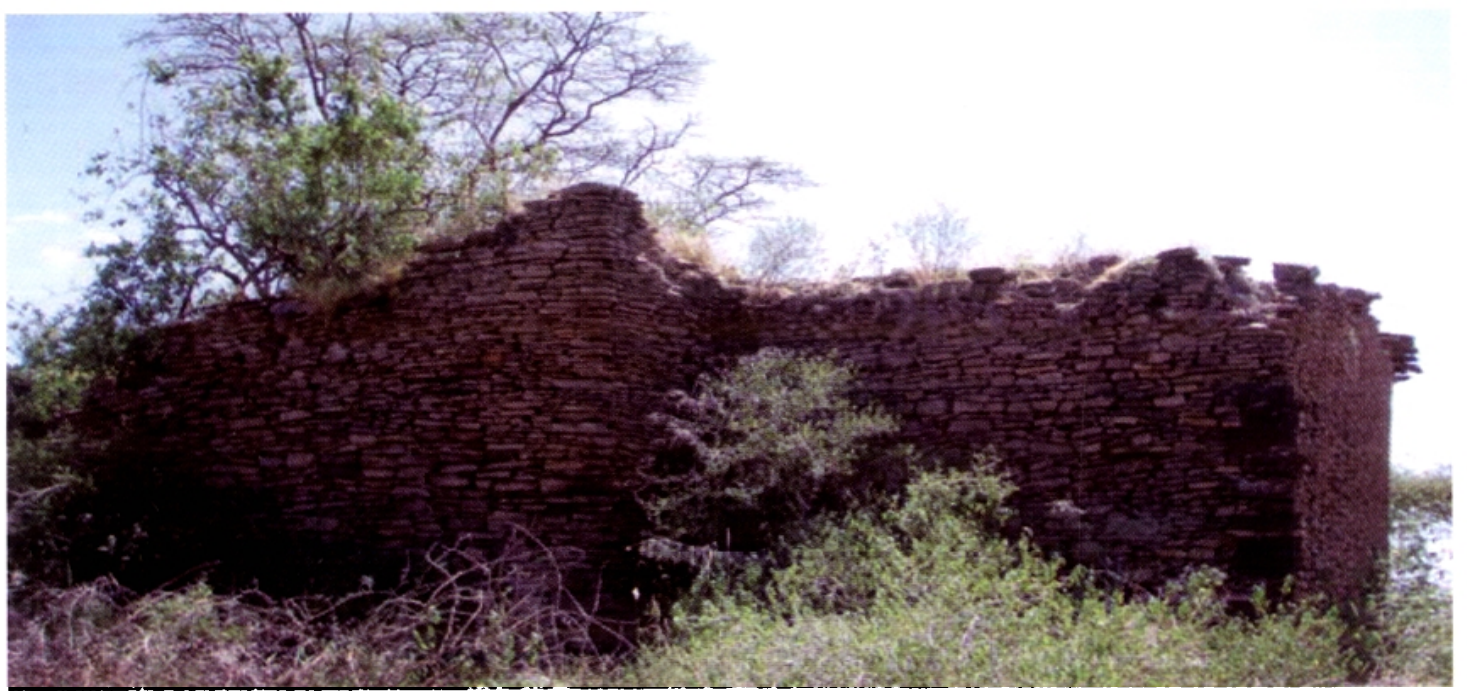

Photo 28 - Nora: mosquée (mur nord avec minaret)

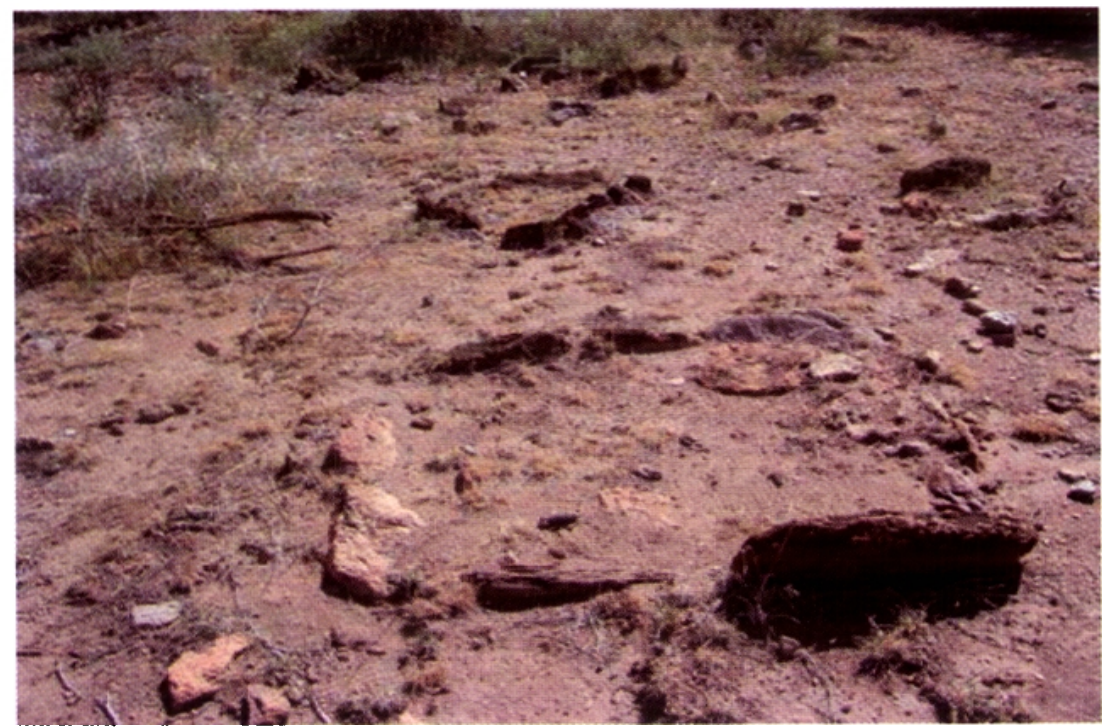

Photo 29-Nora : cimetière 